\title{
NiCo-Metal-Organic Framework and Porous Carbon Interlayer Based Supercapacitors Integrated with a Solar Cell for a Stand-alone Power Supply System
}

\author{
Manoranjan Ojha, ${ }^{a}$ Billy $W u,{ }^{b}$ Melepurath Deepa ${ }^{a}{ }^{*}$ \\ ${ }^{a}$ Department of Chemistry, Indian Institute of Technology Hyderabad, Kandi, Sangareddy-502285, Telangana (India) \\ ${ }^{b}$ Dyson School of Design Engineering, Imperial College, London. SW7 2AZ (United Kingdom)
}

\begin{abstract}
Nickel cobalt-metal-organic frameworks (NiCo-MOF), with a semi-hollow spherical morphology composed of rhombic dodecahedron nanostructures were synthesized by using a scalable and facile wet chemical route. Such a structure endowed the material with open pores, which enabled rapid ion ingress and egress, and the high effective surface area of the MOF allowed the uptake and release of a large number of electrolyte ions during charge-discharge. By combining this NiCo-MOF cathode with a highly porous carbon (PC) anode (derived from the naturally grown and abundantly available bio-waste, namely, palm kernel shells), the resulting $\mathrm{PC} / \mathrm{NiCo}-\mathrm{MOF}$ supercapacitor using an aqueous potassium hydroxide $(\mathrm{KOH})$ electrolyte delivered a capacitance of $134 \mathrm{~F}$ $\mathrm{g}^{-1}$, energy and power densities of $24 \mathrm{Wh} \mathrm{kg}^{-1}$ and $0.8 \mathrm{~kW} \mathrm{~kg}^{-1}$ at $1 \mathrm{~A} \mathrm{~g}^{-1}$, over an operational voltage window of $1.6 \mathrm{~V}$. By employing thin interlayers of PC coated over Whatman filter paper (PC@FP), the modified supercapacitor configuration of PC/PC@FP//PC@FP/NiCo-MOF delivered greatly enhanced performance. This cell delivered a capacitance of $520 \mathrm{~F} \mathrm{~g}^{-1}$ and an energy density of $92 \mathrm{Wh} \mathrm{kg}^{-1}$, improved by nearly-four-fold, compared to the analogous supercapacitor without the interlayers (at the same power and current densities and voltage window), thus evidencing the role of the cost effective, electrically conducting porous carbon interlayers in amplifying the supercapacitor's energy storage capabilities. Further, illumination of white LEDs using a 3-series configuration and the photo-charging of this supercapacitor with a solution processed solar cell, is also demonstrated. The latter confirms its' ability to function as a stand-alone power supply system for electronic/computing devices, that can even operate under medium lighting conditions.
\end{abstract}

Keywords: metal-organic frameworks; porous carbon; interlayer; energy storage; supercapacitor

\section{Introduction}

Microstructural tunability, long range order and synthetically controllable porosity, are the three hallmarks that form the premise for the widespread deployment of metal-organic frameworks (MOFs) in diverse applications spanning: electrocatalysts in fuel cells, cathode or anode scaffolds in rechargeable lithium based batteries, and electrodes in supercapacitors ${ }^{1-4}$. By using facile synthesis strategies, MOFs can be designed into organized crystalline assemblies with open porous channels extending over multiple microns, wherein the porous cavities can serve as reservoirs for anions or cations during charge-discharge, an aspect which comes to prominence, when used as a supercapacitor electrode. MOFs also offer structural tunability, as they can be synthesized in the form of nanosheets, microcubes or micro-spheres with hierarchical morphologies having circular, floral, diamond and triangular shaped open channels ${ }^{5-}$

${ }^{8}$. These elongated unobstructed channels allow easy inflow of electrolyte solution or gel, thereby enabling the ions to specifically adsorb on the electro-active transition metal ion sites on the MOFs, and consequently impart a large specific capacitance (SC) to the energy storage device.

While the above described features of MOFs serve to improve charge storage capabilities of electrodes in supercapacitors via: (1) fast ion uptake and release, and (2) adsorption of a large quanta of ions due to the high effective surface area of the MOFs, there is one major drawback that needs to be surmounted for their efficient use in supercapacitors. This is the low electrical conductivity of MOFs which typically ranges between $10^{-14}$ $-10^{-7} \mathrm{~S} \mathrm{~cm}^{-1}$ depending on nature of metal and co-ordinated ligand. This is generally an outcome of the protocol followed for the framework construction, wherein metal ions are inter-linked via redox inactive, bulky and electronically insulating organic ligands. While this synthesis methodology forms the basis for the required regular porous architecture, it is achieved at the cost of electrical conductivity. By developing MOFs with closely spaced hetero-metallic multi-valent centers, superior redox activity and better electrical conductivity can be achieved in contrast to MOFs composed of single metal ions with long organic moieties. Only, in rare reports, high conductivity for MOFs are reported ${ }^{9,10}$. Ease of scale-up and facile processing are two other pre-requisites that MOFs are expected to satisfy to enable their practical use.

The electronic conductivity of a bimetallic-MOF can also be improved by integrating an optimal proportion of a carbon nano-material with high electrical conductivity $\left(>0.1 \mathrm{~S} \mathrm{~cm}^{-1}\right)$. Electron transport is significantly enhanced throughout the MOF based electrode relative to traditional non-conducting single metal ion MOFs, thus improving the rate capability. A previous report on a (p-type)-CoS $\mathrm{Co}_{2} @ \mathrm{CNT}$ composite showed the composite to have a hierarchical morphology, moderate specific surface area, uniform pore diameter distribution, with a high degree of graphitization, thus bestowing it with a high SC of 825 $\mathrm{F} \mathrm{g} \mathrm{g}^{-1}$ at $0.5 \mathrm{~A} \mathrm{~g} \mathrm{~g}^{-1}$ ) in a $2 \mathrm{M} \mathrm{KOH}$ solution, and a $\sim 83 \% \mathrm{SC}$ retention after 5000 cycles $^{11}$. Yet another report focused on an electrode consisting of Ni-MOF-HCl-180 ${ }^{\circ} \mathrm{C} @$ graphene oxide (GO) sheets, which delivered a SC of $2192 \mathrm{~F} \mathrm{~g}^{-1}$ (at $1 \mathrm{~A} \mathrm{~g}^{-1}$ ), and a SC retention of $\sim 85 \%$ after 3000 cycles. This performance was attributed to improved active material utilization attained by the ability of the Ni-MOF to act as a spacer, as it embeds 
between the GO sheets as discrete micro-spheres, while simultaneously inhibiting the restacking of the GO sheets ${ }^{12}$. Zr-MOF nanocrystals mixed with graphene, exhibited stack and areal capacitances of 0.64 and $5.1 \mathrm{mF} \mathrm{cm} \mathrm{cm}^{-2}$ respectively, which were found to be substantially larger compared to activated carbon or just graphene. This response was a direct result of an enhanced interaction between the $\mathrm{sp}^{2}$-hybridized nitrogens on the nMOF867 with the electrolyte ions, as well as an optimal pore diameter, permitting facile electrolyte infiltration during charge-discharge $^{13}$. Previous reports on 3D-pillared Co(II)-MOF, CeMOF/GO, Ni-MOF on carbon nanowalls and so forth showed high capacitances due to their unique architectures ${ }^{14-17}$. A composite consisting of $3 \mathrm{D}$ porous carbon and $\mathrm{Co}_{3} \mathrm{O}_{4}$ delivered an excellent capacitance of $423 \mathrm{~F} \mathrm{~g}^{-1}$ at $1 \mathrm{~A} \mathrm{~g}^{-1}$ with good rate capability $(85 \%)$ as the hierarchical porous carbon lowered ionic and electron transport resistance ${ }^{18}$. Another study showed that the mesoporous nature of a calcinated MOF consisting of ternary metals (CoNiMn-MOF) produced a high capacitance of $3652 \mathrm{mF} \mathrm{cm}^{-2}$ at a current density of $1 \mathrm{~mA} \mathrm{~cm}^{-2} 19$.

In this study, asymmetric supercapacitors with a porous carbon (PC) electrodes derived from a low cost carbon source, namely, palm kernel shells as anode, and a NiCo-MOF cathode was developed. The PC was coated over filter paper, and used as interlayers in both half-cells to provide additional charge storage. The energy storage characteristics of these cells with interlayers were investigated by probing their diffusion and capacitive behaviour relative to the total capacitance of the PC/PC@FP//PC@FP/NiCo-MOF system. Furthermore, the controlled porosity of the active materials, and the optimal channels afforded by them for unhindered ion-movement, resulted in a cell which offers a good compromise between energy density and power density. Practical utilization of the cell is demonstrated through: (1) charging the same with a solar cell and demonstrating that it can serve as an independent power source and (2) powering white LEDs with the charged supercapacitors.

\section{Experimental}

\section{Chemicals}

Palm kernel shells were collected from local sources. Nickel nitrate hexahydrate $\left(\mathrm{Ni}\left(\mathrm{NO}_{3}\right)_{2} \cdot 6 \mathrm{H}_{2} \mathrm{O}\right)$, cobalt nitrate hexahydrate $\left(\mathrm{Co}\left(\mathrm{NO}_{3}\right)_{2} \cdot 6 \mathrm{H}_{2} \mathrm{O}\right)$, citric acid, 2-methylimidazole, carbon black (CB), poly(vinylidene fluoride) (PVdF, average $\mathrm{M}_{\mathrm{w}}: 5,34,000$ ), $\mathrm{N}$-methyl pyrrolidone (NMP) and potassium hydroxide $(\mathrm{KOH})$ were procured from Merck and used as such. Laminated $\mathrm{Al}, \mathrm{Ni}$ tabs and current collectors were used. Ni foam was procured from Gelon and was used after an acetone wash. Ultrapure water obtained from a Millipore Direct-Q3 UV system (with a resistivity of $\sim 18.2 \mathrm{M} \Omega \mathrm{cm}$ ) was used throughout the experiments.

\section{Synthesis of NiCo-MOF}

$\mathrm{Ni}\left(\mathrm{NO}_{3}\right)_{2} \cdot 6 \mathrm{H}_{2} \mathrm{O}(100 \mathrm{mg}), \mathrm{Co}\left(\mathrm{NO}_{3}\right)_{2} \cdot 6 \mathrm{H}_{2} \mathrm{O}(200 \mathrm{mg})$ and citric acid $(600 \mathrm{mg})$ were dissolved in ultrapure water $(100 \mathrm{~mL})$ and stirred with a magnetic stirrer for $12 \mathrm{~h}$ at room temperature $(\sim 25$ $-27^{\circ} \mathrm{C}$ ). An aqueous solution of 2-methyl imidazole (300 mg) in ultrapure water $(10 \mathrm{~mL})$ was added to the above solution in a dropwise manner and the stirring was continued at $60{ }^{\circ} \mathrm{C}$ for 72 h. A purple colored precipitate was collected by filtration ${ }^{20}$. This precipitate was heated at $800{ }^{\circ} \mathrm{C}$ for $4 \mathrm{~h}$ with a ramping temperature of $200{ }^{\circ} \mathrm{C}$ per hour in a furnace. Finally, the black colored powder sample was collected and labelled as NiCoMOF. The formation of NiCo-MOF is shown through a cartoon in Scheme 1.

\section{Synthesis of porous carbon (PC)}

Palm kernel shells were washed thoroughly by scrubbing them several times in ultrapure water. Hydrothermal synthesis was carried out by taking the cleaned shells in ultrapure water in an autoclave which was maintained at $160{ }^{\circ} \mathrm{C}$ for $12 \mathrm{~h}$. The charred shells were heated at $750{ }^{\circ} \mathrm{C}$ in air with a holding time of $4 \mathrm{~h}$ with a ramping temperature of $200{ }^{\circ} \mathrm{C}$ per hour. The synthesized carbon was activated with a $\mathrm{NaOH}$ solution $(200 \mathrm{mg} \mathrm{NaOH}$ was used with $100 \mathrm{mg}$ of carbon in $5 \mathrm{~mL}$ of ultrapure water) for 12 $\mathrm{h}$ at $60^{\circ} \mathrm{C}$. The resulting porous carbon (PC, black colored product) was washed thoroughly, dried at $60{ }^{\circ} \mathrm{C}$ in an open-air oven and finally stored in a desiccator. The preparation of PC is displayed in Scheme 1.

Detailed descriptions of cell fabrication, fabrication of a photoanode for a solar cell and instrumentation techniques, are provided in the supporting information.

\section{Results and discussion}

\section{Structural and compositional analysis}

The surface morphology of the NiCo-MOF product, prior to the heat treatment, exhibits three-dimensional opaque globular structures (Figure 1a,b), which subsequent to the $800^{\circ} \mathrm{C}$ annealing treatment, transform to discrete translucent spherical structures with well-defined grain boundaries having diameters in the range of 1.5 to $4.5 \mu \mathrm{m}$ (Figure $1 \mathrm{c}, \mathrm{d}$ ), an outcome of controlled organic burnout. Annealing transforms the non-porous compactly packed globules of the NiCo-MOF to distinct rotund shapes encompassing pores, which are conducive towards the ingress and egress of ions, when used as the supercapacitor cathode. On the other hand, for the anode, and the interlayer, porous carbon (PC) was used. Highly porous carbon material was obtained after the heat treatment of palm kernel shells, followed by an alkali exposure, and this is reflected in the large pores with diameters ranging between $360-970 \mathrm{~nm}$ that are generated over tree-trunk like structures (Figure 1e-g). The elemental map of the NiCo-MOF (Figure S1, supporting information) shows the distribution of the different elements: $\mathrm{N}, \mathrm{C}$, $\mathrm{O}, \mathrm{Ni}$ and $\mathrm{Co}$, with proportions of $12.3 \%, 27.6 \%, 8.1 \%, 21.6 \%$ and $30.4 \%$. Ni and Co are uniformly distributed over the spherical shapes. In an earlier report, $\mathrm{Ni}$ and Co proportions of $21 \%$ and $26.3 \%$ were achieved for a $\mathrm{NiCo}-\mathrm{MOF} /$ reduced graphene oxide composite ${ }^{21}$, which are close to the values obtained here.

The overall structures are flaky and have a high surface roughness. Furthermore, the flaky particles that prevail inside the pores can serve as multiple sites for electrolyte ion capture during charge-discharge. PC also doubles up as the interlayer material, and is applied over the filter paper (FP), whereby it not only allows EDL formation, but also allows ions to diffuse through easily and reach either the PC (anode) or NiCo-MOF (cathode).

TEM images of the NiCo-MOF clearly shows the formation of spherical shapes (Figure 2a), and a magnified view of one such sphere (Figure 2b), shows the wall thickness to be of the order of $70 \mathrm{~nm}$, and the outer diameter is approximately 530 to 670 $\mathrm{nm}$. In Figure $2 \mathrm{c}$, the image is taken from a region where the outer shell was thin, and the grain boundaries are clear unlike Figure $2 b$, where the shell is thick. Hence, the slight difference 
in the images. The spheres are porous or semi-hollow in nature, evidenced from the contrast in the images, and a closer inspection of the interior of the spheres reveals the presence of an interconnected network of polyhedral particles (Figure 2c). The presence of the uniformly distributed polyhedrons within the confines of the spherical boundaries confirms that the heat treatment at $800^{\circ} \mathrm{C}$, is not accompanied by the collapse of the framework afforded by the parent bimetallic MOF, but only induces a regulated decomposition of the organic components, culminating in the observed porosity (Figure 2d). This provides the MOF with the appearance of semi-hollow nanocages, where the spherical boundaries enclose the empty spaces separated by the solid polyhedrons that are largely rhombic dodecahedrons; these are illustrated through a cartoon in Scheme 1a. These are characterized by well-defined edges (Figure 2e) and they are highly crystalline as indicated by the observed lattice fringes. Such shapes have been previously observed for ZIF-67@Co-Ni layered double hydroxides ${ }^{20}$. Abundant rich channels, and pores for electrolyte diffusion are the main features of this structure. Adjacent fringe separation of $0.47 \mathrm{~nm}$ is observed (Figure 2f), which aligns with the (111) plane of cubic crystal structure of $\mathrm{NiCo}_{2} \mathrm{O}_{4}$ (PDF: 20-0781). Furthermore, the corresponding selected area electron diffraction (SAED) pattern of the NiCoMOF (Figure 2g) shows bright spots arranged in concentric rings confirming the polycrystalline nature of the material. The spots are assigned to the (111), and (440) planes of the cubic crystal structure.

Highly porous carbon, the anode material, at the nano-level, shows overlapping nanosheet-like structures (Figure 2h-k), which are partially crystalline. While some sheets show no fringes, characteristic of amorphous structures, the others display lattice fringes. The magnified view of the fringes (Figure 21) shows an inter-fringe separation of $0.34 \mathrm{~nm}$, that agrees with the hexagonal structure of graphite. The SAED pattern shows diffuse rings with faint spots, and these are attributed to the (110) and (101) planes of hexagonal graphite.

The XPS survey spectrum of NiCo-MOF shows signals from $\mathrm{C} 1 \mathrm{~s}, \mathrm{O} 1 \mathrm{~s}, \mathrm{Ni2p}, \mathrm{Co} 2 \mathrm{p}$ and $\mathrm{N} 1 \mathrm{~s}$, indicating the presence of these elements in the MOF. Deconvoluted core level spectrum of $\mathrm{Ni} 2 \mathrm{p}$ reveals the spin-orbital split signals with $\mathrm{Ni}_{2} \mathrm{p}_{3 / 2}$ and $\mathrm{Ni} 2 \mathrm{p}_{1 / 2}$ components at 866 and $855.4 \mathrm{eV}$. These peaks are further resolved to yield the contributions from $\mathrm{Ni}^{2+}$ and $\mathrm{Ni}^{3+}$ states and they amount to $51.64 \%$ and $31.73 \%$, respectively. Similarly, the Co2p signal's deconvolution, subsequent to the spinorbital split, shows the $\mathrm{Co}^{3+}(54.7 \%)$ proportion to exceed that of $\mathrm{Co}^{2+}(29.9 \%)$. It is noteworthy that the lower valent $\mathrm{Ni}^{2+}$ and the higher valent $\mathrm{Co}^{3+}$ dominate. The redox peaks observed in the voltammograms (discussed later) arise largely from the oxidation of these species. A weak nitrogen signal is observed with two components at 398 and $400.6 \mathrm{eV}$, arising from C-N and $-\mathrm{NH}$ linkages. The MOF structure is also supplemented with a carbon network, and some nitrogen is retained in the framework, from the imidazole moiety. The $\mathrm{C} 1 \mathrm{~s}$ core level spectrum is deconvoluted into three distinct components at 284.6, 286.2 and $288.4 \mathrm{eV}$ corresponding to the C-C, C-N and $\mathrm{C}-\mathrm{O}$ linkages. The asymmetric deconvoluted $\mathrm{O} 1 \mathrm{~s}$ peak shows two components at 535.4 and $533.7 \mathrm{eV}$, where the lower energy peak stems from the $\mathrm{Ni}^{3+} p^{2+}-\mathrm{O}$ and $\mathrm{Co}^{3+} p^{2+}-\mathrm{O}$ bonds with a contribution of $58.3 \%$, and the higher energy peak originates from the oxygen functionalities flanked to carbon in the porous structure with a contribution of $41.7 \%$. The valence band diagram of the NiCo-MOF is shown in Figure 3f. Near E $=0 \mathrm{eV}$, which is regarded as the Fermi level $\left(\mathrm{E}_{\mathrm{F}}\right)$, the density of states (DOS) approaches zero, and the point of commencement of the rapid rise in the DOS corresponds to the valence band (VB) position of this mixed metal oxide. The difference between $\mathrm{E}_{\mathrm{F}}$ and $\mathrm{VB}$ is found to be $0.2 \mathrm{eV}$, which matches well with a value of 0.23 $\mathrm{eV}$ for $\mathrm{NiCo}_{2} \mathrm{O}_{4}$ in a previous report with a $\mathrm{VB}$ of $5.37 \mathrm{eV}$. Since this oxide is a p-type semiconductor, the Fermi level lies just above the VB, which is located at $\sim 5.1 \mathrm{eV}$ for the NiCo-MOF here. The VB position here, was calculated from the oxidation peak observed in the CV plot of the MOF (Figure 4a). For the NiCo-MOF, $\mathrm{E}_{\mathrm{ox}}=+0.4 \mathrm{~V}$ (versus $\mathrm{Ag} / \mathrm{AgCl}$ ), which amounts to $+0.6 \mathrm{~V}$ versus normal hydrogen electrode. By using the equation, $\mathrm{E}_{\mathrm{VB}}=-(4.5+0.6) \mathrm{eV}$, the $\mathrm{VB}$ position is $5.1 \mathrm{~V}$. Using this $\mathrm{VB}$, the $\mathrm{E}_{\mathrm{F}}$ is calculated to be poised at $4.9 \mathrm{eV}(5.1-0.2 \mathrm{~V})$. The XRD pattern of the NiCo-MOF shows multiple prominent peaks at $2 \theta=18.9^{\circ}, 31.1^{\circ}, 36.7^{\circ}, 38.4^{\circ}, 44.6^{\circ}, 55.4^{\circ}, 59.1^{\circ}, 65$ ${ }^{\circ}$ and $76^{\circ}$ which concur well with the (111), (220), (311), (222), (400), (422), (511), (440) and (533) planes of cubic spinel $\mathrm{NiCO}_{2} \mathrm{O}_{4}$ (JCPDS: 20-0781). The result is consistent with the XPS results.

XPS core level spectrum of $\mathrm{C} 1 \mathrm{~s}$ from porous carbon (PC) reveals three peaks at 284.6, 286.1 and $288.35 \mathrm{eV}$ corresponding to $\mathrm{C}-\mathrm{C}, \mathrm{C}-\mathrm{O}$ and $\mathrm{C}=\mathrm{O}$ linkages, due to functionalization of the carbon network by the alkali. The presence of oxygen functionalities are also confirmed from the deconvoluted O1s spectrum (inset of Figure 3h), which shows two peaks at 531.6, and 534.4 $\mathrm{eV}$ due to the $\mathrm{C}=\mathrm{O}$ and $\mathrm{C}-\mathrm{O}$ groups. The XRD pattern of $\mathrm{PC}$ shows broad peaks at $2 \theta=23.8^{\circ}, 42.5^{\circ}$ and $45.3^{\circ}$, corresponding to the (002), (100) and (101) planes of hexagonal graphite (JCPDS: 75-1621). An additional peak is also observed at $2 \theta=$ $10.9^{\circ}$ which corresponds to $\mathrm{d}=8.5 \AA$. This is larger than the $\mathrm{d}$ spacing in graphite $(3.36 \AA)$ indicating that the interlayer spacing in some regions is enhanced by the functional groups sandwiched in between. A similar peak was previously observed at $8.8 \AA$, for graphite oxide, and it was attributed to the trapped functional groups widening the distance between successive graphene layers ${ }^{22}$.

Raman spectra of NiCo-MOF and PC are shown in Figure S2. Multiple peaks observed for the NiCo-MOF at 182, 455 and 723 $\mathrm{cm}^{-1}$ are due to the $\mathrm{F}_{2 \mathrm{~g}}, \mathrm{E}_{\mathrm{g}}$ and $\mathrm{A}_{1 \mathrm{~g}}$ vibrational modes ${ }^{23-25}$. Other prominent peaks appear above $1000 \mathrm{~cm}^{-1}$ and they are attributed to the vibrations of the $\mathrm{C}-\mathrm{H}, \mathrm{C}-\mathrm{N}, \mathrm{C}-\mathrm{C}$ bonds. PC shows two strong peaks: at 1335 and $1594 \mathrm{~cm}^{-1}$ corresponding to the $\mathrm{D}$ and $\mathrm{G}$ bands, thus aligning with the structure of graphitic carbon which is oxidized in some regions, as confirmed from the XRD and XPS measurements.

The FTIR spectra of the PC and NiCo-MOF are shown in Figure S3. In Figure S3a, for the PC, strong peaks at 1107, 1531, 2314 and $3721 \mathrm{~cm}^{-1}$ correspond to $v(\mathrm{C}-\mathrm{OH})$ of $-\mathrm{COOH}$ groups, $v(\mathrm{C}=\mathrm{C})$ stretching, $v(\mathrm{O}-\mathrm{H})$ stretching from strongly $\mathrm{H}$-bonded $-\mathrm{COOH}$ groups and free $\mathrm{v}(\mathrm{O}-\mathrm{H})$ stretching in the carboxylate groups respectively ${ }^{26-29}$. A peak at $715 \mathrm{~cm}^{-1}$ was observed for the $\mathrm{C}-\mathrm{O}-\mathrm{C}$ stretching of $-\mathrm{COOH}$ groups. Peaks at 1719, (2683, $2818)$ and $3030 \mathrm{~cm}^{-1}$ are due to $v(\mathrm{C}=\mathrm{O}), v\left(-\mathrm{CH}_{2}-\right)$ and $v(=\mathrm{CH})$ respectively. For the NiCo-MOF (Figure $\mathrm{S} 3 \mathrm{~b}$ ), peaks at 560 and $650 \mathrm{~cm}^{-1}$ appear due to the in-plane and out of plane bending modes of $\delta(-\mathrm{NHC})$ and a small peak is observed at $1422 \mathrm{~cm}^{-1}$ which arises due to the $v(\mathrm{C}-\mathrm{N})$ mode $^{30}$. 


\section{Thermogravimetric analysis (TGA) and BET studies}

The phase transformations of the PC and NiCo-MOF were studied by TGA analysis (Figure S3c). For the NiCo-MOF, there is no significant weight loss over the entire temperature range under consideration. The plot is almost flat till $750{ }^{\circ} \mathrm{C}$ with an overall weight loss of only $2.2 \%$. In the case of the PC, there is a rapid weight loss (by $11 \%$ ) at a relatively low temperature $\left(70{ }^{\circ} \mathrm{C}\right)$ due to the removal of water vapor from the surface of the PC. Beyond this temperature, the weight decreases monotonically over the remaining temperature range of 70 to $800^{\circ} \mathrm{C}$, corresponding to approximately $13 \%$ weight loss which is observed after the release of water vapor ${ }^{31}$.

The Brunauer-Emmett-Teller (BET) analysis of the NiCoMOF's data (Figure S4a,c) shows that it follows a type IV nitrogen adsorption/desorption isotherm. This implies that the NiCo-MOF spheres are mesoporous in nature. The surface area of the NiCo-MOF is $320 \mathrm{~m}^{2} \mathrm{~g}^{-1}$ and the average pore diameter is $\sim 7 \mathrm{~nm}$. Our results match well with a previous report on NiCo-MOF nanosheets which too showed a type IV isotherm with a surface area of $380 \mathrm{~m}^{2} \mathrm{~g}^{-1}$ and the nanosheets were observed to be rich with mesopores (pore diameter of $\sim 12 \mathrm{~nm})^{32}$. In another report on $2 \mathrm{D}$ composite nanosheets of $\mathrm{NiCo}_{2} \mathrm{O}_{4} @ Z$ IF-67/GO, the BET-surface area was found to be $175 \mathrm{~m}^{2} \mathrm{~g}^{-133}$. The mesoporosity of the NiCo-MOF structure here, allows uniform penetration of the electrolyte, suggesting of a good number of accessible sites are available for redox reactions.

On the other hand, for the PC, the isotherm is mixed type in character with contributions from types I and IV as per IUPAC classification $^{34}$ (Figure S4b). The profile matches with that observed in a previous report on activated carbon ${ }^{35}$. Thus, the PC is rich in micro-pores and mesopores, which is in line with the morphology and microstructure observed in the SEM and TEM images respectively. The surface area and the average pore diameter are $\sim 565 \mathrm{~m}^{2} \mathrm{~g}^{-1}$ and $\sim 4 \mathrm{~nm}$ respectively. This effective surface area is sufficient enough to accommodate the adsorption of a large number of ions on the active surface, with the mesopores enabling this adsorption via deep and uniform electrolyte permeation.

\section{Electrochemical characterization of supercapacitors}

The charge storage behavior of the materials was examined by firstly selecting a suitable potential window for the asymmetric cell. The potential window was fixed by running cyclic voltammetry (CV) scans at $5 \mathrm{mV} \mathrm{s}^{-1}$ (Figure 4a) where the NiCo-MOF electrode was run from 0 to $0.45 \mathrm{~V}$ and the $\mathrm{PC}$ electrode from -1.15 to $0 \mathrm{~V}$ in a three-electrode system. The $\mathrm{CV}$ of NiCo-MOF (Fig. 4a) shows a broad oxidation peak at about $0.4 \mathrm{~V}$ versus $\mathrm{Ag} / \mathrm{AgCl}$ and in the reverse sweep, two distinct reduction peaks are observed at $\sim 0.22$ and $\sim 0.3 \mathrm{~V}$ versus $\mathrm{Ag} / \mathrm{AgCl}$. The anodic peak arises from the oxidation reactions involving conversion of $\mathrm{Ni}^{2+}$ to $\mathrm{Ni}^{3+}$ and $\mathrm{Co}^{3+}$ to $\mathrm{Co}^{4+}$ whereas in the cathodic scan, the two reductions are distinctly observed at obtained at different voltages ${ }^{36}$.

$\mathrm{NiCo}_{2} \mathrm{O}_{4}+\mathrm{OH}^{-}+\mathrm{H}_{2} \mathrm{O} \leftrightarrow \mathrm{NiOOH}+2 \mathrm{CoOOH}+\mathrm{e}^{-}$

$\mathrm{CoOOH}+\mathrm{OH}^{-} \leftrightarrow \mathrm{CoO}_{2}+\mathrm{H}_{2} \mathrm{O}+\mathrm{e}^{-}$

The PC electrode shows two faint oxidation peaks at -0.21 and $-0.47 \mathrm{~V}$, possibly due to the oxidation of oxygen containing functional groups adjacent to the surface of the material. The plot covers a broad area, and this featureless plot is typical of the capacitive nature of high surface area carbons. The ability of the NiCo-MOF and PC to store and release charge reversibly, by undergoing redox reactions and by electrical double layer formation respectively, over the negative and positive voltage ranges, confirm that $\mathrm{NiCo}-\mathrm{MOF}$ and $\mathrm{PC}$ can function as cathode and anode in an asymmetric supercapacitor. The total potential window for the $\mathrm{PC} / \mathrm{NiCo}-\mathrm{MOF}$ asymmetric cell is $1.6 \mathrm{~V}$ and therefore, all electrochemical measurements like CV, galvanostatic charge-discharge (GCD) and self-discharge were run in this potential window for the asymmetric cell.

To enhance the charge storage capability of the PC//NiCo-MOF asymmetric cell, two additional layers of thin, low-weight PC coated filter paper (FP) strips were incorporated on the cathode and the anode sides, facing the electrolyte absorbed separator. Cells with the following configurations were compared: PC//NiCo-MOF, PC/PC@FP//PC@FP/NiCo-MOF, and PC@FP//PC@FP. CV plots (Figure 4b,c,d) recorded at 5, 20 and $100 \mathrm{mV} \mathrm{s}^{-1}$, show that the symmetric cell based on the pure carbon interlayers (PC@FP//PC@FP) is not highly electroactive. When used independently, the overall current densities are more than ten orders of magnitude lower and the $\mathrm{CV}$ profile is almost flat over the anodic and cathodic branches. But when employed as interlayers in the PC/PC@FP//PC@FP/NiCoMOF PC//NiCo-MOF cell, the enclosed area in the $\mathrm{CV}$ is considerably enhanced, with broad oxidation and reduction peaks observed therein. The anodic portion (at $5 \mathrm{mV} \mathrm{s}^{-1}$ ) reveals two well-separated peaks at +0.26 and $+1.15 \mathrm{~V}$ which are attributed to the $\mathrm{Ni}^{2+} \rightarrow \mathrm{Ni}^{3+}$ and $\mathrm{Co}^{3+} \rightarrow \mathrm{Co}^{4+}$ redox reactions. In the reverse sweep, a small peak is first observed at $\sim 1.13 \mathrm{~V}$ due to the $\mathrm{Co}^{4+} \rightarrow \mathrm{Co}^{3+}$ reduction and for the $\mathrm{Ni}^{3+} \rightarrow \mathrm{Ni}^{2+}$ reduction, no distinct peak is seen, but a broad wave (over 0.6 to $0 \mathrm{~V}$ ) with a minimum at $0.075 \mathrm{~V}$ is observed.

The effect of the interlayer is evidenced from the much larger enclosed areas achieved for the PC/PC@FP//PC@FP/NiCoMOF cell contrasting with that of the $\mathrm{PC} / \mathrm{NiCo}-\mathrm{MOF}$ cell (devoid of interlayers) at any of the three scan rates. The redox behavior of the $\mathrm{PC} / \mathrm{NiCo}-\mathrm{MOF}$ cell is retained largely as observed for the three-electrode system of $\mathrm{PC} / \mathrm{NiCo}-\mathrm{MOF}$ except for a change in the potentials at which the reversible electrochemical reactions occur. In the combined architecture of the PC/PC@FP//PC@FP/NiCo-MOF cell, the profile is almost identical to that of the $\mathrm{PC} / \mathrm{NiCo}-\mathrm{MOF}$ cell but the first oxidation peak (at $\sim 0.3 \mathrm{~V}$ ) appears to be flattened, and the second oxidation peak is shifted a higher oxidation potential of $1.42 \mathrm{~V}$. The reduction peak is observed at $\sim 1.3 \mathrm{~V}$. The interlayers assist in reducing the overpotential for the oxidation reactions, and this could be possibly due to the enhanced availability of hydroxyl anions in the vicinity of the NiCo-MOF electrode. The cartoon in panel " $\mathrm{A}$ " shows the multi-layered structure of this cell, and possible trajectories for cation $\left(\mathrm{K}^{+}\right)$and anion $\left(\mathrm{OH}^{-}\right)$ movement through the porous interlayers during charge. The cell without interlayers does not have this advantage. With increasing scan rate, the $\mathrm{CV}$ patterns remain similar, suggestive of the highly reversible nature of the cell. The pure interlayer based symmetric cell of PC@FP//PC@FP, shows a banana like profile, indicative of charge storage by EDL formation. 
The capacitances from the $\mathrm{CV}$ plots are 7,128 and $350 \mathrm{~F} \mathrm{~g}^{-1}$ for the PC@FP//PC@FP, PC//NiCo-MOF and PC/PC@FP//PC@FP/NiCo-MOF cells (at $5 \mathrm{mV} \mathrm{s}^{-1}$ ), respectively. The GCD curves for the PC@FP//PC@FP cell at 1, 2.5 and $5 \mathrm{~A} \mathrm{~g} \mathrm{~g}^{-1}$ are shown in Figure S5 (supporting information). The capacitances are 3,134 and $518 \mathrm{~F} \mathrm{~g}^{-1}$ for the 3 cells at $1 \mathrm{~A}$ $\mathrm{g}^{-1}$ respectively. This clearly shows that as a stand-alone device, PC@FP//PC@FP is a poor performer with an almost negligible capacitance, but its functionality improves when it is used as an interlayer. This high experimental value suggests that PC@FP, when used in conjunction with the active layers acts as an ionreservoir, allowing facile propagation of ions and good electrolyte penetration during cell operation, thus maximizing charge storage.

GCDs for the PC//NiCo-MOF and PC/PC@FP//PC@FP/NiCoMOF cells, without and with the PC@FP interlayers were compared at current densities of $1,2.5$ and $5 \mathrm{~A} \mathrm{~g}^{-1}$ (Figure 4e,f,g). Here, the GCD profiles for the two cells are similar, and do not show any significant change with increasing current density, inferring good reversibility. In the CV measurements, during oxidation or charging from 0 to $1.6 \mathrm{~V}$, the slope change at $\sim 1 \mathrm{~V}$ corresponds to the onset oxidation potential in the CV plot, and the kink at $\sim 1.3 \mathrm{~V}$, registered during discharge or reduction (from 1.6 to $0 \mathrm{~V}$ ) matches with the onset reduction potential in the CV scan. The variation of capacitance with scan rate as well as current density are shown in Figure 4h,i. The highest capacitance of $350 \mathrm{~F} \mathrm{~g} \mathrm{~g}^{-1}$ is achieved for the cell with the interlayers, and it is 2.7 times higher than that of the $\mathrm{PC} / / \mathrm{NiCo}-\mathrm{MOF}$ cell $\left(128 \mathrm{~F} \mathrm{~g} \mathrm{~g}^{-1}\right)$, without the interlayers, at a scan rate of $5 \mathrm{mV} \mathrm{s}^{-1}$. At higher scan rates, the capacitance of the cell with the interlayers always two times higher than the PC//NiCo-MOF cell. For example, at a scan rate of $100 \mathrm{mV} \mathrm{s}^{-1}$, the cell with interlayers delivers a capacitance of $102 \mathrm{~F} \mathrm{~g} \mathrm{~g}^{-1}$ whereas the $\mathrm{PC} / \mathrm{NiCo}$ MOF cell delivers $58 \mathrm{~F} \mathrm{~g}^{-1}$.

From GCD data, at the same current density of $1 \mathrm{~A} \mathrm{~g}^{-1}$, a maximum capacitance of $518 \mathrm{~F} \mathrm{~g}^{-1}$ is achieved for the $\mathrm{PC} / \mathrm{NiCo}-$ MOF and PC/PC@FP//PC@FP/NiCo-MOF cell with interlayers, which is 3.8 times greater than that of the $\mathrm{PC} / / \mathrm{NiCo}-\mathrm{MOF}$ cell $\left(134 \mathrm{~F} \mathrm{~g}^{-1}\right)$. On examining the rate performance over an applied current density of 1 to $5 \mathrm{~A} \mathrm{~g}^{-1}$, the cell with interlayers provides 3.8 to 3 times higher capacitance than the one without interlayers. Furthermore, the capacitance decreases by $50 \%$ and $67 \%$ (over 1 to $5 \mathrm{~A} \mathrm{~g}^{-1}$ ) for the cells with and without interlayers respectively.

It should be noted that when preparing the NiCo-MOF electrode, a small proportion of PC was added. This is because of the low electrical conductivity of the NiCo-MOF $(0.32 \mu \mathrm{S} / \mathrm{cm}$, $)$, which led to poor cell level performance. Therefore, a small amount of PC was incorporated with the NiCo-MOF to enhance the electron transport across the NiCo-MOF cross-section during charge-discharge (conductivity improved by 4500 times), while simultaneously ensuring that the amount of NiCo-MOF present in the electrode ( $75 \mathrm{wt} \%$, considering only active material) is high enough such that the electrochemical performance is primarily dictated by the NiCo-MOF. Carbons usually give a rectangular profile, and their GCDs are also perfectly triangu$\operatorname{lar}^{37}$. Here, for the cells with NiCo-MOF, the CV profiles as well the GCD plots were characteristic of NiCo-MOF's redox behavior, thus confirming this hypothesis. The role of the small proportion of PC added here is simply to enhance the conductivity of the electrode.

\section{Mechanistic aspects of charge storage}

From the above discussion, it is evident that the cell purely composed of the interlayers (PC@FP//PC@FP), delivered very poor $\mathrm{SC}$. However, when integrated into the asymmetric cell assembly of PC//NiCo-MOF to yield the PC/PC@FP//PC@FP/NiCoMOF cell, the resulting architecture showed a remarkably enhanced storage behavior (in terms of rate response, enclosed voltammetric area, and capacitances). In order to understand the role of the interlayers in ameliorating the storage behavior, the following set of equations were used to quantify the individual contributions to total capacitance from the (1) pseudocapacitive (redox reactions based) and (2) EDL formation mechanisms. $\mathrm{CV}$ data of electroactive materials is used in the equations provided below ${ }^{38}$.

$$
\begin{aligned}
& i(v)=a v^{b} \\
& \log (i(v))=\log (a)+b \log (v)
\end{aligned}
$$

In equations (6) and (7), both a and $b$ are adjustable parameters. $v$ and $i(v)$ are scan rate and peak current at a specific scan rate. Parameter $b$ was calculated from the slope of equation 7 by plotting $\log (i(v))$ vs. $\log (v)$. It provides information about the kinetics of the electrochemical charge storage mechanism ${ }^{39}$, where the roles of "non-Faradaic"-surface capacitive effects and the "Faradaic"-diffusion controlled redox reactions can be identified separately. The value of $b=0.5$ and 1 are the two ideal conditions for a slow diffusion-controlled faradic process (such as in battery materials) and of fast charging-discharging EDLC process as well as fast surface redox process (such as in pseudocapacitive materials) respectively. Any value in-between these two distinct values of 0.5 and 1 suggests a transition process where the charge storage process follows both mechanisms, i.e., the material- (i) accumulates electrostatic charge on its' surface which is dependent on the applied potential, and (ii) it undergoes redox reactions by accepting or releasing electrons. Although it will be difficult to draw a clear boundary in a real case between the two types of materials, it can be predicted by analysing the closeness of $b$ towards 0.5 or 1 . Generally, smaller values of $b$ are obtained for battery materials whereas they are higher for capacitive materials. In this study (Figure 5b), the calculated $b$ values are 0.79 and 0.83 by considering anodic and cathodic peaks respectively for the $\mathrm{PC} / / \mathrm{NiCo}-\mathrm{MOF}$ cell, confirming the cell's propensity to behave as a psuedocapacitor. In the case of the cell with the interlayers, i.e., the PC/PC@FP//PC@FP/NiCo-MOF cell, b values are 0.74 and 0.73 by considering anodic and cathodic peak respectively.

These values are less close to " 1 " and closer to " 0.5 " compared to values obtained for the $\mathrm{PC} / \mathrm{NiCo}-\mathrm{MOF}$ cell. In the PC/PC@FP//PC@FP/NiCo-MOF cell, both EDL formation and the redox process occur via the diffusion of cations or anions across the PC@FP interlayer, which is approximately 20 $\mu \mathrm{m}$ thick on either side, and then further propagation through the bulk of the PC anode or the NiCo-MOF cathode. Once the ions reach the NiCo-MOF electrode, faradaic reactions involving charge transfer and transport occur. Simultaneously, fast adsorption of electrolyte ions onto the surface or in the vicinal region of the electrode surface also contributes to the overall ca- 
pacitance. This contribution is lower for the cell with the interlayers because chances of rapidly forming EDL are greater when the pure electroactive PC or NiCo-MOF electrodes flank the electrolyte soaked separator as is the case in the $\mathrm{PC} / \mathrm{NiCo}-$ MOF cell. In the cell with interlayers, the ions under a directed (electric) field have more pore volume to traverse through, and have access to much larger number of active sites (for PC@FP, PC@Ni and NiCo-MOF@Ni), which maximizes capacitance, but it does this through the "diffusion" mechanism. This can be visualized through the schematics shown in Figure 5a' and a".

This study also explains how the PC/PC@FP//PC@FP/NiCoMOF cell containing the interlayers delivers a capacitance superior to that of the PC//NiCo-MOF cell (devoid of the interlayers). It is crucial to elucidate this, for the stand-alone interlayers based cell of PC@FP//PC@FP delivers very poor performance. Based on the rationale that the PC/PC@FP//PC@FP/NiCoMOF cell's behavior falls in-between that of batteries and supercapacitors, it is anticipated that this cell will simultaneously deliver high energy density as well as high power density. For a better understanding of cell performance, a quantitative approach is desirable. For the surface dominant non-Faradaic charge accumulation/release, the current varies linearly with scan rate and for a diffusion controlled process, the current shows a direct dependence on the square root of scan rate. These contributions were identified by using the following equations.

$i(V)=i_{\text {cap }}+i_{\text {diff }}=k_{1} v+k_{2} v^{1 / 2}$

Or

$i(V) / v^{1 / 2}=k_{1} v^{1 / 2}+k_{2}$

In (8), $i_{\text {cap }}$ and $i_{\text {diff }}$ are the current contributions from the surface confined capacitive- and diffusion controlled- processes respectively. The constants $k_{1}$ and $k_{2}$ are estimated from the slopes and the intercept of a linear plot of $i(V) / v^{1 / 2}$ vs. $v^{1 / 2}$ (Figure 5a) by using equation 9 . The area under the curve for only capacitive processes are marked in shaded lines for $\mathrm{PC} /$ PC@FP//PC@FP/NiCo-MOF and PC//NiCo-MOF cells at a scan rate of $5 \mathrm{mVs}^{-1}$ (Figure $5 \mathrm{c}, \mathrm{d}$ ). It is observed that the shaded capacitive region extended slightly beyond the diffusive region, with the exploration of this expanded in the supporting information (Figure S6).

Non-Faradaic capacitance of $36 \mathrm{~F} \mathrm{~g} \mathrm{~g}^{-1}(28 \%)$ out of $128 \mathrm{~F} \mathrm{~g}^{-1}$ was obtained for the PC//NiCo-MOF cell and $30 \mathrm{~F} \mathrm{~g}^{-1}(8.5 \%)$ out of $350 \mathrm{~F} \mathrm{~g}^{-1}$ was achieved for the PC/PC@FP//PC@FP/NiCoMOF cell at a scan rate of $5 \mathrm{mV} \mathrm{s}^{-1}$. The contribution of stored charge from the capacitive and diffusion processes for both cells at different scan rates are shown in Figure 5e,f. It is concluded from the above estimation that the amount of capacitance contribution for both cells is the same from the EDL process (Capacitive). In general, an EDL supercapacitor provides high power density while suffering from low energy density. Thus from the above study, it is predicted that by changing the architecture from PC//NiCo-MOF to PC/PC@FP//PC@FP/NiCo$\mathrm{MOF}$, the power density is expected to remain unaltered while energy density may increase by 2.7 to 3.5 times, when the interlayers are incorporated, as in the PC/PC@FP//PC@FP/NiCo-MOF cell. This calculation was done by subtracting the EDL capacitance from total capacitance for both cells at all scan rates.

The charge stored $\left(q^{*}\right)$ in the electrode or cell, typically, increases with decreasing scan rate $(v)^{40}$. Therefore, for a fast surface reaction process (where $v \rightarrow \infty$ ) or a slow diffusion control process (where $v \rightarrow 0$ ), the value of $q^{*}$ can be calculated under the two extreme conditions. When $v \rightarrow \infty$, the magnitude of charge stored is low, as diffusion is a slow process, and the available time is not enough for sufficient ion-percolation in/out of the pores. As a consequence, $q_{d}^{*}$ decreases and shows a linear variation with the reciprocal of square root of scan rate $\left(v^{-1 / 2}\right)$. Thus, by using equation 10 , by extrapolating the plot, the intercept, $q_{s}^{*}$ can be calculated, where $q_{v \rightarrow \infty}^{*}=q_{s}^{*}$. On the other hand, when $v \rightarrow 0$ i.e., ample time is available for diffusion, thus allowing maximum ion-permeation across the electrode. The total charge storage $\left(q_{m}^{*}\right)$ under these conditions will be high. Thus, $1 / q^{*}(v)$ varies linearly with $v^{1 / 2}$. From equation 11 , by extrapolating the graph, $q_{m}^{*}$ can be calculated from the intercept, where $q_{d}^{*}=\left(q_{m}^{*}-q_{s}^{*}\right)$.

$q^{*}(v)=q_{s}^{*}+q_{d}^{*}=q_{v \rightarrow \infty}^{*}+k\left(v^{-1 / 2}\right)^{*}$

$1 / q^{*}(v)=1 / q_{m}^{*}+k^{\prime}\left(v^{1 / 2}\right)^{*}$

Hence, by using the above method, the maximum theoretical capacitance from surface phenomena and diffusion can be evaluated. The calculated $q_{s}^{*}$ values of $\mathrm{PC} / / \mathrm{NiCo}-\mathrm{MOF}$ and $\mathrm{PC} /$ PC@FP//PC@FP/NiCo-MOF cells are $76 \mathrm{C}\left(47 \mathrm{~F} \mathrm{~g}^{-1}\right)$ and 66 $\mathrm{C}\left(41 \mathrm{~F} \mathrm{~g} \mathrm{~g}^{-1}\right)$ whereas $q_{d}^{*}$ values are $1806 \mathrm{C}\left(1128 \mathrm{~F} \mathrm{~g} \mathrm{~g}^{-1}\right)$ and 265 $\mathrm{C}\left(166 \mathrm{~F} \mathrm{~g}^{-1}\right)$ respectively.

\section{Energy storage parameters enhanced by interlayers}

Ragone plots (energy density $(\mathrm{E})$ versus power density $(\mathrm{P})$ ) for both cells are presented in Figure 6a. The maximum energy density obtained for the $\mathrm{PC} / / \mathrm{NiCo}-\mathrm{MOF}$ cell is $24 \mathrm{Wh} \mathrm{kg}^{-1}$, which increases by $\sim 4$ times to $92 \mathrm{Wh} \mathrm{kg}^{-1}$, for the PC/PC@FP//PC@FP/NiCo-MOF cell at the same power density of $0.8 \mathrm{~kW} \mathrm{~kg}^{-1}$. At a higher power density of $4 \mathrm{~kW} \mathrm{~kg}^{-1}$, the $\mathrm{PC} / \mathrm{NiCo}-\mathrm{MOF}$ cell delivers $\mathrm{E}=16 \mathrm{Wh} \mathrm{kg}^{-1}$ whereas the cell with the interlayers (PC/PC@FP//PC@FP/NiCo-MOF) produces $\mathrm{E}=46 \mathrm{Wh} \mathrm{kg}^{-1}$. Here the PC@FP interlayer serves as an ion reservoir, which ensures the availability of a larger numbers of ions to diffuse to the cathode and anode electrodes, during charge-discharge. This ionic reservoir therefore, not only ensures sufficient charge carriers to access the full capacitance of the electrodes, but also maintains the concentration of charge carriers to maintain a sufficiently high ionic conductivity. Simultaneously, owing to its capability to conduct electrons, as evident from a low sheet resistance of $\sim 200 \Omega \mathrm{cm}^{-2}$, the interlayer also acts as a secondary current collector, which provides a driving force for electrons to propagate, and for every electron, a charge balancing cation is inserted from the electrolyte. This interlayer, due to its combination with the NiCo-MOF@Ni or the PC@Ni electrode, allows maximum absorption of electrolyte ions, thus enhancing the charge storage properties.

Comparison of the materials prepared in this study with the results of other MOF based metal oxide supercapacitors from literature is presented in the Ragone plot in Figure $6 \mathrm{a}^{20,41-46}$. The MOF cell with interlayers, prepared in this work, clearly outperforms most of reported cells in literature, thus showcasing that this approach of using interlayers improves the storage response significantly. Self-discharge profiles of two cells are compared by charging at a current density of $4 \mathrm{~mA}$ with the cell potential assessed as a function of time (Figure 6b). For both the cells, the potential steadily drops to $1.40 \mathrm{~V}$ in the first $20 \mathrm{~s}$ and further declines to $1.2 \mathrm{~V}$ after $2.5 \mathrm{~min}$. For the PC//NiCoMOF cell, the potential drops to half of its initial value in $\sim 5.5$ 
min. and it is discharged to $0 \mathrm{~V}$ in $20.5 \mathrm{~min}$. This drop rate is slowed down in the PC/ PC@FP//PC@FP/NiCo-MOF cell, as it reaches half of its initial voltage within $\sim 9.5 \mathrm{~min}$ and takes to $38 \mathrm{~min}$ to reach $0.3 \mathrm{~V}$. This slower discharge, proves that the interlayer is effective at accumulating charge and but at the same time having a low self-discharge current. Here the PC@FP interlayer serves as an ion reservoir, which ensures the availability of a larger numbers of ions to diffuse in the electrolyte. This ionic reservoir therefore, not only ensures sufficient charge carriers to access the full capacitance of the electrodes, but also maintains a high concentration of charge carriers. The self-discharge therefore occurs over a longer time-span compared to the cell without the interlayers. A cycle stability for capacitance retention of $88 \%$ is registered for the cell with interlayers, and the cell without the interlayers, shows a capacity retention of $92 \%$, after 10,000 cycles at a fixed current density of $5 \mathrm{~A} \mathrm{~g}^{-1}$ (Figure $6 \mathrm{c}$ ).

Nyquist plots of the cells with and without the interlayers are compared before and after 10,000 charge-discharge cycles in Figure 6d,f, where Figure 6e shows the plot for the cell based purely on the interlayers, the PC@FP//PC@FP one. These were recorded over a frequency range of $10^{6}$ to $0.01 \mathrm{~Hz}$ by superimposing an AC amplitude of $20 \mathrm{mV}$ over the open circuit potential of a given cell. The equivalent circuit of $[\mathrm{R}\{\mathrm{RC}\} \mathrm{W}]$ used for fitting the data is displayed in the inset of Figure 6d. Despite the multiple layers in the PC/ PC@FP//PC@FP/NiCo-MOF cell, the overall impedance is lower, compared to the $\mathrm{PC} / \mathrm{NiCo}-$ MOF cell. This is due to the fact that the sheet resistance of the electrolyte wetted PC@FP electrode is reasonably low: $200 \Omega$ $\mathrm{cm}^{-2}$, and therefore ion and electron transfer or propagation are facile in the PC/ PC@FP//PC@FP/NiCo-MOF cell. It must be noted, that when the PC@FP interlayer with the absorbed electrolyte is in direct electrical contact with the $\mathrm{PC}$ or NiCo-MOF electrode, it behaves differently from how it functions when used alone. This is also palpable from the EIS parameters: the pure-interlayer based cell, exhibits a very high bulk resistance of $118 \Omega \mathrm{cm}^{2}$, indicating that the electron injection contacts, at both terminals of the cell, offer high resistances. In contrast, the bulk resistances of the MOF cells without and with the interlayers are quite low: $\sim 0.8$ and $\sim 1.8 \Omega \mathrm{cm}^{2}$ (Table1), exemplifying that despite the slight increase in the contact resistance introduced into the cell by the inclusion of the PC@FP interlayers, the charge transfer resistance, which is the most important factor that controls cell performance, is in fact lowered by the presence of the twin interlayers. The charge transfer resistances are 8.8 and $7.5 \Omega \mathrm{cm}^{2}$ for the cells without and with interlayers, and $\mathrm{Y}_{\mathrm{o}}$, the measure of diffusional conductance are 5.6 and $43.8 \mathrm{mS}$ $\mathrm{s}^{1 / 2} \mathrm{~cm}^{-2}$ respectively. These values again confirm that the interlayer enable ease of ion-movement. With cycling, the charge transfer resistance increases, and this is also reflected in the change of the profiles to a distorted semi-circle followed by the slanting line. Post-cycling, charge transfer resistances are 19 and $36 \Omega \mathrm{cm}^{2}$ for the cells without and with the interlayers. This increase is an outcome of possible interfacial changes caused by the repetitive insertion and extraction of ions from the electrodes.

\section{Role of PC@FP}

The role of PC@FP is further illustrated from electrical conduction studies. I-V characteristics of PC@FP were recorded in a
SS/PC@FP/SS configuration (SS: Stainless Steel) over a voltage window of -2 to $+2 \mathrm{~V}$ (Figure $7 \mathrm{a}$ ). The plot is linear indicating an Ohmic behavior confirming that electrical current is driven by intrinsic charge carriers (electrons) in the material. From the slope of the straight line fit, and by using the following equation: $\sigma=$ slope or $(\Delta \mathrm{I} / \Delta \mathrm{V}) \times \mathrm{d}$ (thickness) /a (area), conductivity $(\sigma)$ is determined to be $13 \mathrm{mS} \mathrm{cm}^{-1}$, which is the DC electronic conductivity. Ionic and electronic conductivities were also estimated from impedance plots, recorded for the free-standing PC@FP interlayer in a $\mathrm{KOH}$ solution, and for the $\mathrm{SS} / \mathrm{KOH} / \mathrm{SS}$ configuration (Figure $7 \mathrm{~b}, \mathrm{c}$ ). The following equations are used for calculating $\mathrm{R}_{\mathrm{e}}$ and $\mathrm{R}_{\text {ion. }}$.

$$
\begin{gathered}
1 /\left(\mathrm{R}_{\mathrm{h}}-\mathrm{R}_{\mathrm{s}}\right)=1 / \mathrm{R}_{\mathrm{e}}+1 / \mathrm{R}_{\text {ion }} \\
3\left(\mathrm{R}_{\mathrm{l}}-\mathrm{R}_{\mathrm{s}}\right)=\mathrm{R}_{\mathrm{e}}+\mathrm{R}_{\text {ion }}
\end{gathered}
$$

$R_{\mathrm{s}}$ is the solution resistance, which is obtained from the high frequency abscissa intercept of the $\mathrm{SS} / \mathrm{KOH} / \mathrm{SS}$ cell. $\mathrm{R}_{\mathrm{h}}$ is obtained after subtracting $R_{s}$ from the high frequency intercept of the PC@FP/KOH cell. $\mathrm{R}_{l}$ is the limiting low frequency impedance, obtained by extrapolating a tangent to the abscissa. $R_{e}$ and $R_{\text {ion }}$ were calculated to be 1.7 and $20.4 \Omega \mathrm{cm}^{2}$. While the electronic resistance is lower than the ionic one, but both resistances are reasonably low. From $\mathrm{R}_{\text {ion }}$, the ionic conductivity is estimated to be $1.1 \mathrm{mS} \mathrm{cm}^{-1}$. The electron conductivity calculated from $\mathrm{R}_{\mathrm{e}}$ is $14 \mathrm{mS} \mathrm{cm}$, which is almost the same as the one obtained from the I-V data. These values affirm the ability of the self-standing PC@FP interlayer to conduct not just electrons but also $\mathrm{K}^{+}$or $\mathrm{OH}^{-}$ions efficiently across the thickness. Such an interlayer, which is cost-effective, easy to fabricate and scale-up, and is capable of efficient dual conduction is ideal for supercapacitor and even battery applications. The proposed mechanism for this is as follows: in this interlayer, the electrically insulating cellulose based filter paper fibers are completely coated by the electrically conducting porous carbon particles which are interconnected, thus allowing electron delocalization via the overlapping $\pi$-orbitals which are oriented above and below the planes in the graphitic structure of the PC. Concurrently, the pores in the filter paper allow deep electrolyte penetration and under applied bias, the electrolyte cations or anions tether via electrostatic attraction to the PC coated fibers of the paper.

The conductivities of the NiCo-MOF and NiCo-MOF/PC were estimated from two-probe I-V measurements (Figure 7f). The powder compound was placed in a square cavity made by using double sided tape on SS foil and the device was connected in the SS/sample/SS configuration for the experiment. From the linear plots of NiCo-MOF and NiCo-MOF/PC, the estimated conductivities of NiCo-MOF and NiCo-MOF/PC are $0.32 \mu \mathrm{S}$ $\mathrm{cm}^{-1}$ and $1.44 \mathrm{mS} \mathrm{cm}^{-1}$ respectively. $\mathrm{PC}$ increases the conductivity of the NiCo-MOF, which can increase the rate performance. Although MOFs have a much lower conductivity, but this conductivity is due to mixed valence states of the nickel $\left(\mathrm{Ni}^{2+/ 3+}\right)$ and cobalt $\left(\mathrm{Co}^{4+3+}\right)$, which allows inter-valence charge transfer.

\section{LED illumination from charged PC/PC@FP//PC@FP/NiCo-MOF supercapacitors}

To demonstrate the application potential of the PC/PC@FP//PC@FP/NiCo-MOF supercapacitor, CV, GCD and EIS plots of one such cell, 2- and 3- cells connected in series ( $2 \mathrm{~S}$ and $3 \mathrm{~S}$ ) are shown in Figure $\mathrm{S} 7$. In the $\mathrm{CV}$ plots, for $2 \mathrm{~S}$ and 
$3 \mathrm{~S}$ configurations, the finer features of the oxidation and reduction phenomena are obscured, possibly to the complexity of the overall assembly, and as anticipated, the overall anodic and cathodic current densities reduce proportionally with increasing number of cells connected in series. The rectangular CV profiles obtained for $2 \mathrm{~S}$ and $3 \mathrm{~S}$ ratify the capacitive nature of the configurations. GCD plots show that the $2 \mathrm{~S}$ and $3 \mathrm{~S}$ configurations could be easily charged to $\sim 3$ and $\sim 5 \mathrm{~V}$ respectively, with capacitances of 57 and $40 \mathrm{~F} \mathrm{~g} \mathrm{~g}^{-1}$, when operated under a current density of $5 \mathrm{~A} \mathrm{~g}^{-1}$. The $3 \mathrm{~S}$ cell could deliver a capacitance of 40 $\mathrm{F} \mathrm{g}^{-1}$, implying that it could be used for small-scale powering applications. EIS parameter comparison shows that the bulk resistance increases with increasing number of cells, induced by the increasing number of electrical contacts, and their resistances add up to give this cumulative $R_{b}$ of $7.8 \Omega \mathrm{cm}^{2}$, for $3 S$ compared to $1.7 \Omega \mathrm{cm}^{2}$ obtained for 1 cell. Charge transfer resistance also experiences an increase to $\sim 63 \Omega \mathrm{cm}^{2}$ for $3 \mathrm{~S}$, again due to an increased number of electrode/electrode interfaces that prevail in this multiple cell configuration. The capacitance values and EIS parameters for $1 \mathrm{~S}, 2 \mathrm{~S}$ and $3 \mathrm{~S}$ cells are summarised in Table $S 1$ (available in supporting information). A white LED panel was connected to a $3 \mathrm{~S}$ configuration of PC/PC@FP//PC@FP/NiCo-MOF supercapacitors. During the charging phase, which was accomplished using a potentiostat, the LED was disconnected (panel (d)). Once the $3 \mathrm{~S}$ supercapacitors were charged to $\sim 4.8 \mathrm{~V}$, the external source connections were removed, the white LED was connected to the cell, and it lighted up brightly (panel (e)). A few seconds late, the LED dims (panel (f)), indicating that the discharging of the supercapacitors.

\section{Demonstration of a stand-alone low cost power supply sys- tem}

The PC/PC@FP//PC@FP/NiCo-MOF supercapacitor was used in conjunction with a solution processed solar cell with the objective of demonstrating that it can work as an independent power source for electronic or computing devices. For the solar cell, a $\mathrm{TiO}_{2} / \mathrm{CdS}$ electrode was fabricated using a wet chemical route, and it was employed as the photoanode in the solar cell (Figure 8a). The active electrode area was maintained at $3 \times 1.8$ $\mathrm{cm}^{2}$. The PC@Ni foam electrode with an equivalent active area was used as the counter electrode (CE) for the solar cell. The solar cell was assembled in a sandwich configuration with $\mathrm{TiO}_{2} / \mathrm{CdS}$ as the photoanode, PC@Ni foam as the CE, and a GF/D separator permeated with a few drops of polysulfide solution (prepared by dissolving $1 \mathrm{M}$ sulfur and $1 \mathrm{M} \mathrm{Na}_{2} \mathrm{~S}$ in deionized water), as the electrolyte which was affixed between the two electrodes. $\mathrm{KOH}$ cannot be used in the solar cell as the electrolyte, for in the solar cell, the electrolyte has to serve as a hole scavenger. This role is played by the $\mathrm{S} / \mathrm{S}^{2-}$ species. The edges were sealed with an ethyl cyanoacrylate epoxy sealant. The current density $(\mathrm{J})$-applied potential $(\mathrm{V})$ characteristics were measured for the solar cell under 1 sun $\left(100 \mathrm{~mW} \mathrm{~cm}^{-2}\right)$ and 0.5 sun $\left(50 \mathrm{~mW} \mathrm{~cm}^{-2}\right)$ irradiance (Figure $\left.8 \mathrm{~b}\right)$. The cell shows almost negligible current density in dark, implying that the currents produced under irradiance are predominantly an outcome of the light driven processes. In this cell, upon illumination, electronhole separation occurs in CdS quantum dots, which serve as the photosensitizers. The photoexcited electrons in $\mathrm{CdS}$ cascade into the conduction band of $\mathrm{TiO}_{2}$, and finally reach the $\mathrm{CE}$ via the external circuit, where they are consumed for the reduction of $\mathrm{S}_{\mathrm{n}}{ }^{2-}$ species. The reduced $\mathrm{nS}^{2-}$ species reach the photoanode and regenerate $\mathrm{CdS}$. Under 1 and 0.5 sun, the short circuit current densities $\left(\mathrm{J}_{\mathrm{SC}}\right)$ are 4.9 and $2.35 \mathrm{~mA} \mathrm{~cm}^{-2}$, but the open circuit voltages $\left(\mathrm{V}_{\mathrm{OC}}\right)$ are equal $(\sim 854 \mathrm{mV})$, indicating that with increasing illumination, there is a higher degree of electron-hole separation in $\mathrm{CdS}$, and therefore the photocurrent density increases. The fill factor (FF) of the solar cell, determined from the expression: $\mathrm{FF}=\mathrm{V}_{\max } \times \mathrm{J}_{\max } / \mathrm{V}_{\mathrm{OC}} \times \mathrm{J}_{\mathrm{SC}}$, is also enhanced from 0.59 to 0.65 , and these two factors improve its' power conversion efficiency (PCE). The PCE was calculated using the expression: $\mathrm{PCE}=\mathrm{V}_{\mathrm{OC}} \times \mathrm{J}_{\mathrm{SC}} \times \mathrm{FF} / \mathrm{P}_{\text {input }} . \mathrm{P}_{\text {input }}$ is the incident solar irradiance power. PCEs of the solar cell are 2.36 and $2.75 \%$ respectively under 0.5 and 1 sun respectively. For such a large area solution processed solar cell with an exposed area of 5.4 $\mathrm{cm}^{2}$, the value under 1 sun exposure, is much higher than the values reported for large area quantum dot based solar cells. In the past, for a $1 \mathrm{~cm}^{2} \mathrm{TiO}_{2} / \mathrm{CuZnSnS}$ solar cell, a value of 1.91 $\%^{47}$ and for another cell with carbonate treated $\mathrm{TiO}_{2}-\mathrm{CdS}$ $\mathrm{Au} @$ poly(acrylic acid) photoanode, and having an exposed area of $4 \mathrm{~cm}^{2}$, a value of $1.06 \%$ were achieved ${ }^{48}$.

In order to photo-charge the supercapacitor, the two electrodes of the resultant solar cell: $\mathrm{TiO}_{2} / \mathrm{CdS} / \mathrm{S}^{2-}, \mathrm{S} / \mathrm{PC} @ \mathrm{Ni}$ foam were connected to the two electrodes of the asymmetric PC/PC@FP//PC@FP/NiCo-MOF supercapacitor, as shown in Figure $8 \mathrm{a}$. The two ends of the supercapacitor were also connected to the potentiostat to monitor the photo-charging and galvanostatic discharge (under dark). When the solar cell is exposed to 1 sun $\left(100 \mathrm{~mW} \mathrm{~cm}^{-2}\right)$, the photocurrent produced by the solar cell is channelled to the PC/PC@FP//PC@FP/NiCoMOF supercapacitor, which are electrically connected. This photocurrent charges the supercapacitor to $\sim 0.83 \mathrm{~V}$ (Figure 8c), without the application of any external bias or current. The charging time is $\sim 147 \mathrm{~s}$. Since the $\mathrm{V}_{\mathrm{OC}}$ of the solar cell is 854 $\mathrm{mV}$, the supercapacitor is charged to nearly the same potential. The light is switched off, and the discharging of the supercapacitor was performed at three different current densities in dark. From the discharge curves, the SC was calculated to be 294, 240 and $216 \mathrm{~F} \mathrm{~g} \mathrm{~g}^{-1}$, at current densities of 1,2 and $3 \mathrm{~A} \mathrm{~g}^{-1}$. In terms of areal capacitances, these values are 588,480 and $432 \mathrm{mF} \mathrm{cm}^{-}$ ${ }^{2}$ under 2, 4 and $6 \mathrm{~mA} \mathrm{~cm}^{-2}$. The SCs are larger than SCs reported for photo-supercapacitors in the past, at similar current densities. A photosupercapacitor (PSC) integrated by s perovskite: $\mathrm{CH}_{3} \mathrm{NH}_{3} \mathrm{PbI}_{3}$ and poly(aniline)/carbon nanotubes (CNT) using a CNT bridge delivered a maximum SC of $103.4 \mathrm{~F} \mathrm{~g}^{-1}$ $\left(422 \mathrm{mF} \mathrm{cm}^{-2}\right)^{49}$. A carbon supported graphene/poly(3,4-ethylenedioxythiophene) (PEDOT) supercapacitor integrated with a solar cell delivered a maximum areal capacitance of $40.44 \mathrm{mF}$ $\mathrm{cm}^{-2} 50$. In an another report on a PSC where a solar cell with $\mathrm{TiO}_{2} / \mathrm{S}, \mathrm{N}$ - doped graphene particles/CdS-S/S ${ }^{2-} /$ silica gelpoly(3,4-propylenedioxythiophene)/carbon microspheres-Bi nanoflakes (PProDOT/CMS-BiNF) configuration connected with a symmetric PProDOT/CMS-BiNF supercapacitor gave a

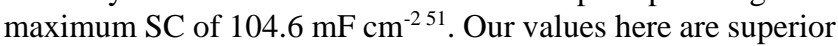
to above-mentioned values. The maximum energy density herein is $14 \mathrm{Wh} \mathrm{kg}^{-1}$ at a power density of $1.25 \mathrm{~kW} \mathrm{~kg}^{-1}$. This study clearly proves that the PC/PC@FP//PC@FP/NiCo-MOF supercapacitor can easily work in tandem with a photovoltaic cell, and such a stand-alone assembly can find application as an uninterrupted power supply system for internet of things having inter-related computing devices, consumer electronic devices and so forth. 


\section{Conclusions}

NiCo-MOF constituted by rhombic dodecahedrons at the nanolevel assemble under kinetic control to acquire semi-hollow spherical structures, was synthesized. This MOF was endowed with open channels that allowed fast ion insertion and extraction, and the large effective surface area of the MOF permitted the infiltration of a large number of cations or anions during charge-discharge. The NiCo-MOF cathode was coupled with a PC anode synthesized from low cost, environmentally friendly, amply available palm kernel shells. The ensuing $\mathrm{PC} / / \mathrm{NiCo}-$ MOF supercapacitor encompassing an aqueous $\mathrm{KOH}$ electrolyte, delivered a capacitance of $134 \mathrm{~F} \mathrm{~g} \mathrm{~g}^{-1}$, energy and power densities of $24 \mathrm{Wh} \mathrm{kg}^{-1}$ and $0.8 \mathrm{~kW} \mathrm{~kg}^{-1}$ at $1 \mathrm{~A} \mathrm{~g} \mathrm{~g}^{-1}$, over a working potential window of $1.6 \mathrm{~V}$. This performance was improved by incorporating free-standing interlayers of PC@FP which allowed a greater proportion of charge accumulation owing to its high mixed electronic and ionic conductivity. Furthermore, the additional pore volume, leading to additional charge carriers in the electrolyte, allowed the concentration of the ions to be maintained, thus prolonging the discharge time, and enhancing the capacity. The improved supercapacitor PC/PC@FP//PC@FP/NiCo-MOF architecture delivered a capacitance of $520 \mathrm{~F} \mathrm{~g}^{-1}$ and an energy density of $92 \mathrm{Wh} \mathrm{kg}^{-1}$, increased by nearly-four-fold compared to the supercapacitor without the interlayers (at the same power and current densities and voltage window). A panel of white LEDs was illuminated using a $3 \mathrm{~S}$ configuration and photo-charging of this supercapacitor with a solution processed solar cell was also demonstrated. The latter exemplified that this cell can be used to develop stand-alone powering systems for consumer electronic or computing devices.

\section{Supporting information}

Experimental methods: Cell fabrication, fabrication of a photoanode for a solar cell and instrumental techniques, Raman spectra, FTIR spectra, BET, TGA of NiCo-MOF and PC, GCD plots of a PC@FP//PC@FP cell, capacitive and diffusion contributions recorded at $1 \mathrm{mV} \mathrm{s}^{-1}$, electrochemical characteristics and impedance fit parameters of $1,2 \mathrm{~S}$, and $3 \mathrm{~S}$ cells. This material is available free of charge at http://pubs.acs.org.

\section{Corresponding Author}

\section{*Melepurath Deepa}

Department of Chemistry, Indian Institute of Technology Hyderabad, Kandi-502285, Sangareddy, Telangana (India).

Email: mdeepa@chy.iith.ac.in, Tel: +91-40-23016005.

Acknowledgements

Financial support from the Department of Science \& Technology of India (Project: India-UK Center for education and research in clean energy (IUCERCE), Grant no. DST/RCUK/JVCCE/2015/04 (1) (G)) is gratefully acknowledged by M. Deepa and M Ojha. M.O. is thankful to University Grants Commission (UGC) for the grant of senior research fellowship. This work was also financially supported by the EPSRC Joint UK-India Clean Energy Centre (JUICE) (EP/P003605/1) for Dr. Billy Wu. We also thank DST-FIST (SR/FST/ETI-421/2016) for the SEM studies.

\section{References}

(1) Ajoyan, Z.; Marino, P.; Howarth, A. J. Green Applications of Metal-Organic Frameworks. CrystEngComm 2018, $20 \quad$ (39), 5899-5912. https://doi.org/10.1039/C8CE01002A.

(2) Goswami, S.; Ma, L.; Martinson, A. B. F.; Wasielewski, M. R.; Farha, O. K.; Hupp, J. T. Toward MetalOrganic Framework-Based Solar Cells: Enhancing Directional Exciton Transport by Collapsing Three-Dimensional Film Structures. ACS Appl. Mater. Interfaces 2016, 8 (45), 30863-30870. https://doi.org/10.1021/acsami.6b08552.

(3) Majewski, M. B.; Peters, A. W.; Wasielewski, M. R.; Hupp, J. T.; Farha, O. K. Metal-Organic Frameworks as Platform Materials for Solar Fuels Catalysis. ACS Energy Lett. 2018, 3 (3), 598-611. https://doi.org/10.1021/acsenergylett.8b00010.

(4) Kuyuldar, S.; Genna, D. T.; Burda, C. On the Potential for Nanoscale Metal-Organic Frameworks for Energy Applications. J. Mater. Chem. A 2019, 7 (38), 2154521576. https://doi.org/10.1039/C9TA09896H.

(5) Stock, N.; Biswas, S. Synthesis of Metal-Organic Frameworks (MOFs): Routes to Various MOF Topologies, Morphologies, and Composites. Chem. Rev. 2012, 112 (2), 933-969. https://doi.org/10.1021/cr200304e.

(6) Wang, X.; Feng, J.; Bai, Y.; Zhang, Q.; Yin, Y. Synthesis, Properties, and Applications of Hollow Micro/Nanostructures. Chem. Rev. 2016, 116 (18), 1098311060. https://doi.org/10.1021/acs.chemrev.5b00731.

(7) Hwang, J.; Ejsmont, A.; Freund, R.; Goscianska, J.; Schmidt, B. V. K. J.; Wuttke, S. Controlling the Morphology of Metal-Organic Frameworks and Porous Carbon Materials: Metal Oxides as Primary Architecture-Directing Agents. Chem. Soc. Rev. 2020, 49(11), 3348-3422. https://doi.org/10.1039/C9CS00871C.

(8) Xiao, X.; Zou, L.; Pang, H.; Xu, Q. Synthesis of Micro/Nanoscaled Metal-Organic Frameworks and Their Direct Electrochemical Applications. Chem. Soc. Rev. 2020, 49 (1), 301-331. https://doi.org/10.1039/C7CS00614D.

(9) Bhardwaj, S. K.; Bhardwaj, N.; Kaur, R.; Mehta, J.; Sharma, A. L.; Kim, K.-H.; Deep, A. An Overview of Different Strategies to Introduce Conductivity in Metal-Organic Frameworks and Miscellaneous Applications Thereof. J. Mater. Chem. A 2018, 6 (31), 14992-15009. https://doi.org/10.1039/C8TA04220A.

(10) Xie, L. S.; Skorupskii, G.; Dincă, M. Electrically Conductive Metal-Organic Frameworks. Chem. Rev. 2020. https://doi.org/10.1021/acs.chemrev.9b00766.

(11) Zou, K.-Y.; Liu, Y.-C.; Jiang, Y.-F.; Yu, C.-Y.; Yue, M.-L.; Li, Z.-X. Benzoate Acid-Dependent Lattice Dimension of Co-MOFs and MOF-Derived $\mathrm{CoS}_{2} @ \mathrm{CNTs}$ with Tunable Pore Diameters for Supercapacitors. Inorg. Chem. 2017, 56 (11), 6184-6196. https://doi.org/10.1021/acs.inorgchem.7b00200.

(12) Zhou, Y.; Mao, Z.; Wang, W.; Yang, Z.; Liu, X. In-Situ Fabrication of Graphene Oxide Hybrid Ni-Based Metal-Organic Framework (Ni-MOFs@GO) with Ultrahigh Capacitance as Electrochemical Pseudocapacitor Materials. ACS Appl. Mater. Interfaces 2016, 8 (42), 
28904-28916.

https://doi.org/10.1021/acsami.6b10640.

(13) Choi, K. M.; Jeong, H. M.; Park, J. H.; Zhang, Y.-B.; Kang, J. K.; Yaghi, O. M. Supercapacitors of Nanocrystalline Metal-Organic Frameworks. ACS Nano 2014, 8 (7), 7451-7457. https://doi.org/10.1021/nn5027092.

(14) Sanati, S.; Abazari, R.; Morsali, A.; Kirillov, A. M.; Junk, P. C.; Wang, J. An Asymmetric Supercapacitor Based on a Non-Calcined 3D Pillared Cobalt(II) Metal-Organic Framework with Long Cyclic Stability. Inorg. Chem. 2019, 58 (23), 16100-16111. https://doi.org/10.1021/acs.inorgchem.9b02658.

(15) Ramachandran, R.; Xuan, W.; Zhao, C.; Leng, X.; Sun, D.; Luo, D.; Wang, F. Enhanced Electrochemical Properties of Cerium Metal-Organic Framework Based Composite Electrodes for High-Performance Supercapacitor Application. RSC Adv. 2018, 8 (7), 3462-3469. https://doi.org/10.1039/C7RA12789H.

(16) Deng, T.; Zhang, W.; Arcelus, O.; Wang, D.; Shi, X.; Zhang, X.; Carrasco, J.; Rojo, T.; Zheng, W. Vertically Co-Oriented Two Dimensional Metal-Organic Frameworks for Packaging Enhanced Supercapacitive Performance. Commun. Chem. 2018, 1 (1), 1-9. https://doi.org/10.1038/s42004-017-0005-8.

(17) Kim, H. S.; Kang, M. S.; Yoo, W. C. Boost-up Electrochemical Performance of MOFs via Confined Synthesis within Nanoporous Carbon Matrices for Supercapacitor and Oxygen Reduction Reaction Applications. J. Mater. Chem. A 2019, 7 (10), 5561-5574. https://doi.org/10.1039/C8TA12200H.

(18) Li, S.; Yang, K.; Ye, P.; Ma, K.; Zhang, Z.; Huang, Q. Three-Dimensional Porous Carbon $/ \mathrm{Co}_{3} \mathrm{O}_{4}$ Composites Derived from Graphene/Co-MOF for High Performance Supercapacitor Electrodes. Applied Surface Science 2020, 503, 144090. https://doi.org/10.1016/j.apsusc.2019.144090.

(19) Li, S.; Duan, Y.; Teng, Y.; Fan, N.; Huo, Y. MOFDerived Tremelliform $\mathrm{Co}_{3} \mathrm{O}_{4} / \mathrm{NiO} / \mathrm{Mn}_{2} \mathrm{O}_{3}$ with Excellent Capacitive Performance. Applied Surface Science 2019, 478, 247-254. https://doi.org/10.1016/j.apsusc.2019.01.140.

(20) Xiao, Z.; Bao, Y.; Li, Z.; Huai, X.; Wang, M.; Liu, P.; Wang, L. Construction of Hollow Cobalt-Nickel Phosphate Nanocages through a Controllable Etching Strategy for High Supercapacitor Performances. ACS Appl. Energy Mater. 2019, 2 (2), 1086-1092. https://doi.org/10.1021/acsaem.8b01627.

(21) Beka, L. G.; Bu, X.; Li, X.; Wang, X.; Han, C.; Liu, W. A 2D Metal-Organic Framework/Reduced Graphene Oxide Heterostructure for Supercapacitor Application. RSC Adv. 2019, 9 (62), 36123-36135. https://doi.org/10.1039/C9RA07061C.

(22) Gao, W.; Alemany, L. B.; Ci, L.; Ajayan, P. M. New Insights into the Structure and Reduction of Graphite Oxide. Nature Chemistry 2009, 1 (5), 403-408. https://doi.org/10.1038/nchem.281.

(23) Jabeen, N.; Xia, Q.; Yang, M.; Xia, H. Unique CoreShell Nanorod Arrays with Polyaniline Deposited into Mesoporous $\mathrm{NiCo}_{2} \mathrm{O}_{4}$ Support for High-Performance
Supercapacitor Electrodes. ACS Appl. Mater. Interfaces 2016, 8 (9), 6093-6100. https://doi.org/10.1021/acsami.6b00207.

(24) Jin, J.; Zheng, Y.; Huang, S.; Sun, P.; Srikanth, N.; Kong, L. B.; Yan, Q.; Zhou, K. Directly Anchoring 2D NiCo Metal-Organic Frameworks on Few-Layer Black Phosphorus for Advanced Lithium-Ion Batteries. $J$. Mater. Chem. A 2019, 7 (2), 783-790. https://doi.org/10.1039/C8TA09327J.

(25) Liu, Z.-Q.; Xiao, K.; Xu, Q.-Z.; Li, N.; Su, Y.-Z.; Wang, H.-J.; Chen, S. Fabrication of Hierarchical Flower-like Super-Structures Consisting of Porous NiCo2O4 Nanosheets and Their Electrochemical and Magnetic Properties. RSC Adv. 2013, 3 (13), 43724380. https://doi.org/10.1039/C3RA23084H.

(26) Bhandari, S.; Deepa, M.; Srivastava, A. K.; Joshi, A. G.; Kant, R. Poly(3,4-Ethylenedioxythiophene)-Multiwalled Carbon Nanotube Composite Films: StructureDirected Amplified Electrochromic Response and Improved Redox Activity. J. Phys. Chem. B 2009, 113 (28), 9416-9428. https://doi.org/10.1021/jp9012976.

(27) Banwell. Fundamentals of Molecular \& Spectroscopy; Tata McGraw-Hill Education, 2001.

(28) Atieh, M. A.; Bakather, O. Y.; Al-Tawbini, B.; Bukhari, A. A.; Abuilaiwi, F. A.; Fettouhi, M. B. Effect of Carboxylic Functional Group Functionalized on Carbon Nanotubes Surface on the Removal of Lead from Water. Bioinorg. Chem. Appl. 2010. https://doi.org/10.1155/2010/603978.

(29) Hou, J.; Jiang, K.; Shen, M.; Wei, R.; Wu, X.; Idrees, F.; Cao, C. Micro and Nano Hierachical Structures of BiOI/Activated Carbon for Efficient Visible-LightPhotocatalytic Reactions. Sci. Rep. 2017, 7 (1), 11665. https://doi.org/10.1038/s41598-017-12266-X.

(30) Trivedi, M. K.; Dahryn Trivedi, A. B.; Gunin Saikia, G. N. Physical and Structural Characterization of Biofield Treated Imidazole Derivatives. Nat Prod Chem Res 2015, $03 \quad$ (05), 1000187. https://doi.org/10.4172/2329-6836.1000187.

(31) Das, D.; Samal, D. P.; Bc, M. Preparation of Activated Carbon from Green Coconut Shell and Its Characterization. J Chem Eng Process Technol 2015, 06 (05), 17. https://doi.org/10.4172/2157-7048.1000248.

(32) Thangasamy, P.; Shanmuganathan, S.; Subramanian, V. A NiCo-MOF Nanosheet Array Based Electrocatalyst for the Oxygen Evolution Reaction. Nanoscale $A d v . \quad 2020, \quad 2 \quad$ (5), 2073-2079. https://doi.org/10.1039/D0NA00112K.

(33) Kuang, Y.; Chen, C.; Li, K.; Hao, B.; Ma, J.; Liao, Y.; Mao, H.; Huo, F. Encapsulating $\mathrm{NiCo}_{2} \mathrm{O}_{4}$ inside MetalOrganic Framework Sandwiched Graphene Oxide 2D Composite Nanosheets for High-Performance LithiumIon Batteries. Nanoscale 2019, 11 (32), 15166-15172. https://doi.org/10.1039/C9NR02787D.

(34) Thommes, M.; Kaneko, K.; Neimark, A. V.; Olivier, J. P.; Rodriguez-Reinoso, F.; Rouquerol, J.; Sing, K. S. W. Physisorption of Gases, with Special Reference to the Evaluation of Surface Area and Pore Size Distribution (IUPAC Technical Report). Pure Appl. Chem. 2015, 87 (9-10), 1051-1069. https://doi.org/10.1515/pac-2014-1117. 
Kumar, A.; Jena, H. M. Preparation and Characterization of High Surface Area Activated Carbon from Fox Nut (Euryale Ferox) Shell by Chemical Activation with H3PO4. Results in Physics 2016, 6, 651-658. https://doi.org/10.1016/j.rinp.2016.09.012.

(36) Zhang, J.; Liu, F.; Cheng, J. P.; Zhang, X. B. Binary Nickel-Cobalt Oxides Electrode Materials for HighPerformance Supercapacitors: Influence of Its Composition and Porous Nature. ACS Appl. Mater. Interfaces 2015, 7 (32), 17630-17640. https://doi.org/10.1021/acsami.5b04463.

(37) Gao, S.; Wang, K.; Du, Z.; Wang, Y.; Yuan, A.; Lu, W.; Chen, L. High Power Density Electric DoubleLayer Capacitor Based on a Porous Multi-Walled Carbon Nanotube Microsphere as a Local Electrolyte Micro-Reservoir. Carbon 2015, 92, 254-261. https://doi.org/10.1016/j.carbon.2015.04.034.

(38) Wang, J.; Polleux, J.; Lim, J.; Dunn, B. Pseudocapacitive Contributions to Electrochemical Energy Storage in $\mathrm{TiO}_{2}$ (Anatase) Nanoparticles. J. Phys. Chem. C 2007, $111 \quad$ (40), 14925-14931. https://doi.org/10.1021/jp074464w.

(39) Liu, J.; Wang, J.; Xu, C.; Jiang, H.; Li, C.; Zhang, L.; Lin, J.; Shen, Z. X. Advanced Energy Storage Devices: Basic Principles, Analytical Methods, and Rational Materials Design. Adv. Sci. 2018, 5 (1), 1700322. https://doi.org/10.1002/advs.201700322.

(40) Ardizzone, S.; Fregonara, G.; Trasatti, S. "Inner" and "Outer" Active Surface of $\mathrm{RuO}_{2}$ Electrodes. Electrochim. Acta 1990, 35 (1), 263-267. https://doi.org/10.1016/0013-4686(90)85068-X.

(41) Wang, Y.; Liu, Y.; Wang, H.; Liu, W.; Li, Y.; Zhang, J.; Hou, H.; Yang, J. Ultrathin NiCo-MOF Nanosheets for High-Performance Supercapacitor Electrodes. ACS Appl. Energy Mater. 2019, 2 (3), 2063-2071. https://doi.org/10.1021/acsaem.8b02128.

(42) Xiao, Y.; Wei, W.; Zhang, M.; Jiao, S.; Shi, Y.; Ding, S. Facile Surface Properties Engineering of High-Quality Graphene: Toward Advanced Ni-MOF Heterostructures for High-Performance Supercapacitor Electrode. ACS Appl. Energy Mater. 2019, 2 (3), 2169-2177. https://doi.org/10.1021/acsaem.8b02201.

(43) Liu, Y.; Wang, Y.; Wang, H.; Zhao, P.; Hou, H.; Guo, L. Acetylene Black Enhancing the Electrochemical Performance of NiCo-MOF Nanosheets for Supercapacitor Electrodes. Appl. Surf. Sci. 2019, 492, 455-463. https://doi.org/10.1016/j.apsusc.2019.06.238.

(44) Zhang, J.; Chen, J.; Luo, Y.; Chen, Y.; Li, Z.; Shi, J.; Wang, G.; Wang, R. MOFs-Assisted Synthesis of Hierarchical Porous Nickel-Cobalt Nitride Heterostructure for Oxygen Reduction Reaction and Supercapacitor. ACS Sustainable Chem. Eng. 2020, 8 (1), 382-392. https://doi.org/10.1021/acssuschemeng.9b05655.

(45) Wang, Y.; Huang, J.; Xiao, Y.; Peng, Z.; Yuan, K.; Tan, L.; Chen, Y. Hierarchical Nickel Cobalt Sulfide Nanosheet on MOF-Derived Carbon Nanowall Arrays with Remarkable Supercapacitive Performance. Carbon 2019, 147, 146-153. https://doi.org/10.1016/j.carbon.2019.02.082.

(46) Du, Y.; Li, G.; Chen, M.; Yang, X.; Ye, L.; Liu, X.; Zhao, L. Hollow Nickel-Cobalt-Manganese Hydroxide
Polyhedra via MOF Templates for High-Performance Quasi-Solid-State Supercapacitor. Chem. Eng. J. 2019, 378 , 122210 . https://doi.org/10.1016/j.cej.2019.122210.

(47) Sadeghnejad, A.; Lu, L.; Cline, J.; Ozdemir, N. K.; Snyder, M. A.; Kiely, C. J.; McIntosh, S. In Situ Biomineralization of $\mathrm{Cu}_{\mathrm{x}} \mathrm{Zn}_{\mathrm{y}} \mathrm{Sn}_{\mathrm{z}} \mathrm{S}_{4}$ Nanocrystals within $\mathrm{TiO}_{2}$-Based Quantum Dot Sensitized Solar Cell Anodes. ACS Appl. Mater. Interfaces 2019, 11 (49), 45656-45664. https://doi.org/10.1021/acsami.9b15545.

Kumar, P. N.; Kolay, A.; Deepa, M.; Shivaprasad, S. M.; Srivastava, A. K. Stability, Scale-up, and Performance of Quantum Dot Solar Cells with CarbonateTreated Titanium Oxide Films. ACS Appl. Mater. Interfaces 2017, 9 (30), 25278-25290. https://doi.org/10.1021/acsami.7b05726.

(49) Liu, R.; Liu, C.; Fan, S. A Photocapacitor Based on Organometal Halide Perovskite and PANI/CNT Composites Integrated Using a CNT Bridge. J. Mater. Chem. A 2017, 5 (44), 23078-23084. https://doi.org/10.1039/C7TA06297D.

(50) Gao, K.; Ti, D.; Zhang, Z. A Photocapacitor with High Working Voltage and Energy Density. Sustainable Energy Fuels 2019, 3 (8), 1937-1942. https://doi.org/10.1039/C9SE00325H.

(51) Das, A.; Ojha, M.; Subramanyam, P.; Deepa, M. A Poly(3,4-Propylenedioxythiophene)/Carbon MicroSphere-Bismuth Nanoflake Composite and Multifunctional Co-Doped Graphene for a Benchmark Photo-Supercapacitor. Nanoscale Adv. 2020, 2, 2929-2942 https://doi.org/10.1039/D0NA00103A. 
Table 1: Fitted EIS parameters for symmetric cells before and after 10000 charge-discharge cycles.

\begin{tabular}{|l|l|l|l|}
\hline Cell & State of the cell & $\mathrm{R}_{\mathrm{b}}\left(\Omega \mathrm{cm}^{2}\right)$ & $\mathrm{R}_{\mathrm{ct}}\left(\Omega \mathrm{cm}^{2}\right)$ \\
\hline PC@FP//PC@FP & Fresh & 118 & 76 \\
\hline PC//NiCo-MOF & Fresh & 0.77 & 8.8 \\
\cline { 2 - 4 } & After $10^{4}$ cycles & 1.50 & 19 \\
\hline PC/ PC@FP//PC@FP/NiCo-MOF & Fresh & 1.73 & 7.5 \\
\cline { 2 - 4 } & After $10^{4}$ cycles & 1.55 & 36 \\
\hline
\end{tabular}




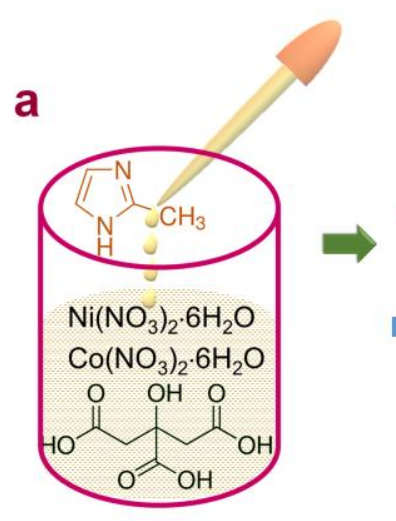

b

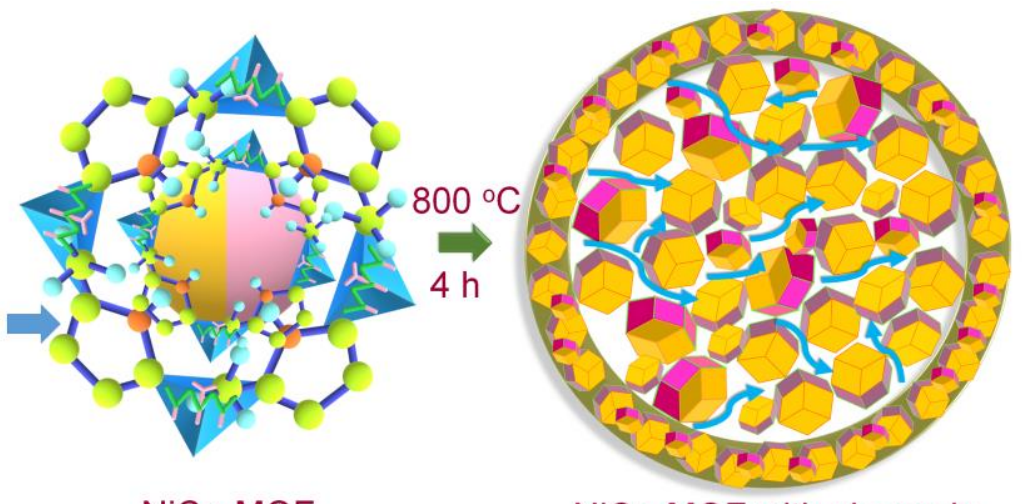

NiCo-MOF
NiCo-MOF with channels for ion movement ?

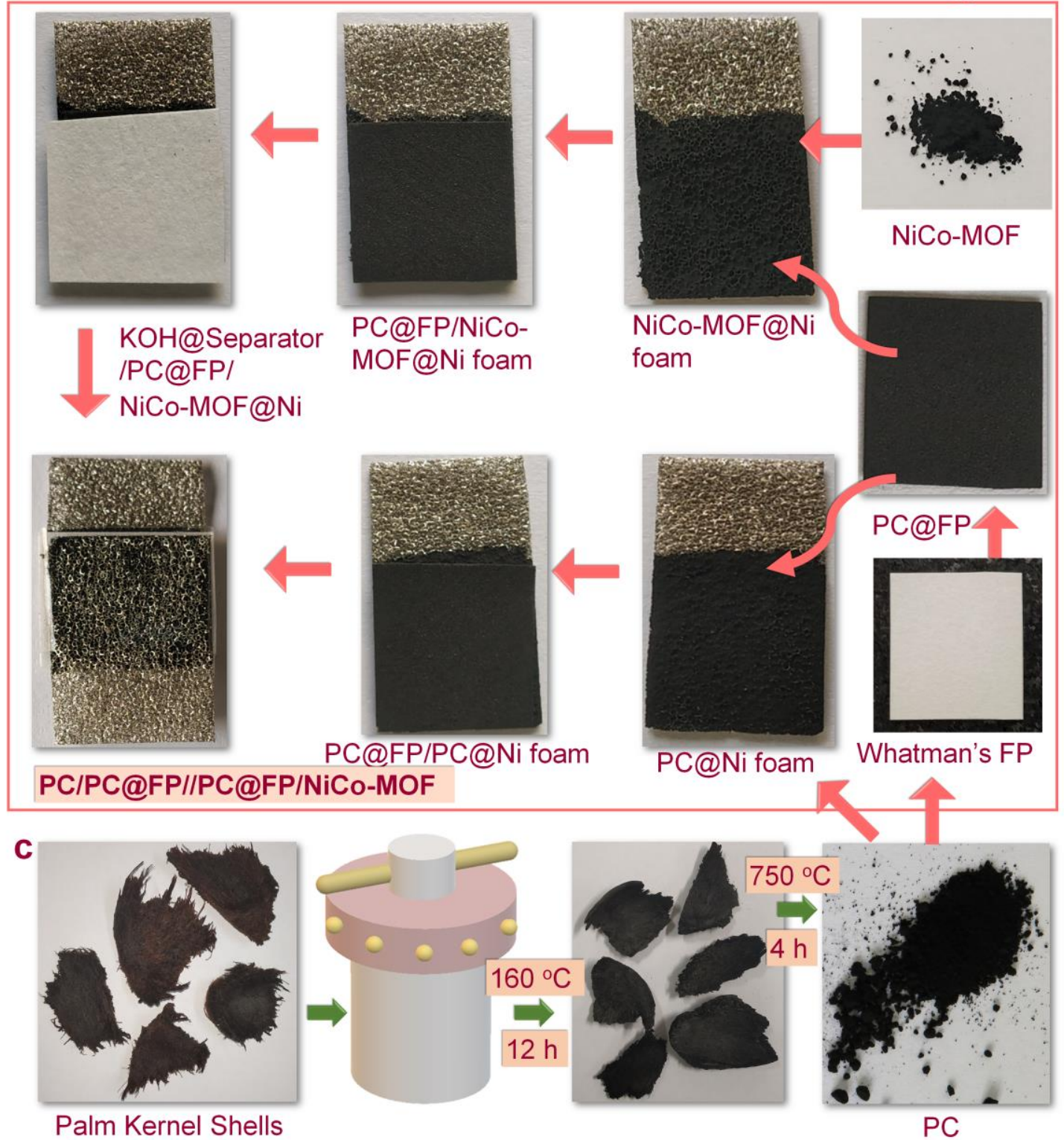

Scheme 1. (a) Cartoons representing the synthesis of NiCo-MOF, (b) illustration of the fabrication of PC/ PC@FP//PC@ FP/NiCo-MOF cell using photographs, and (c) preparation schematic of PC from palm kernels. 


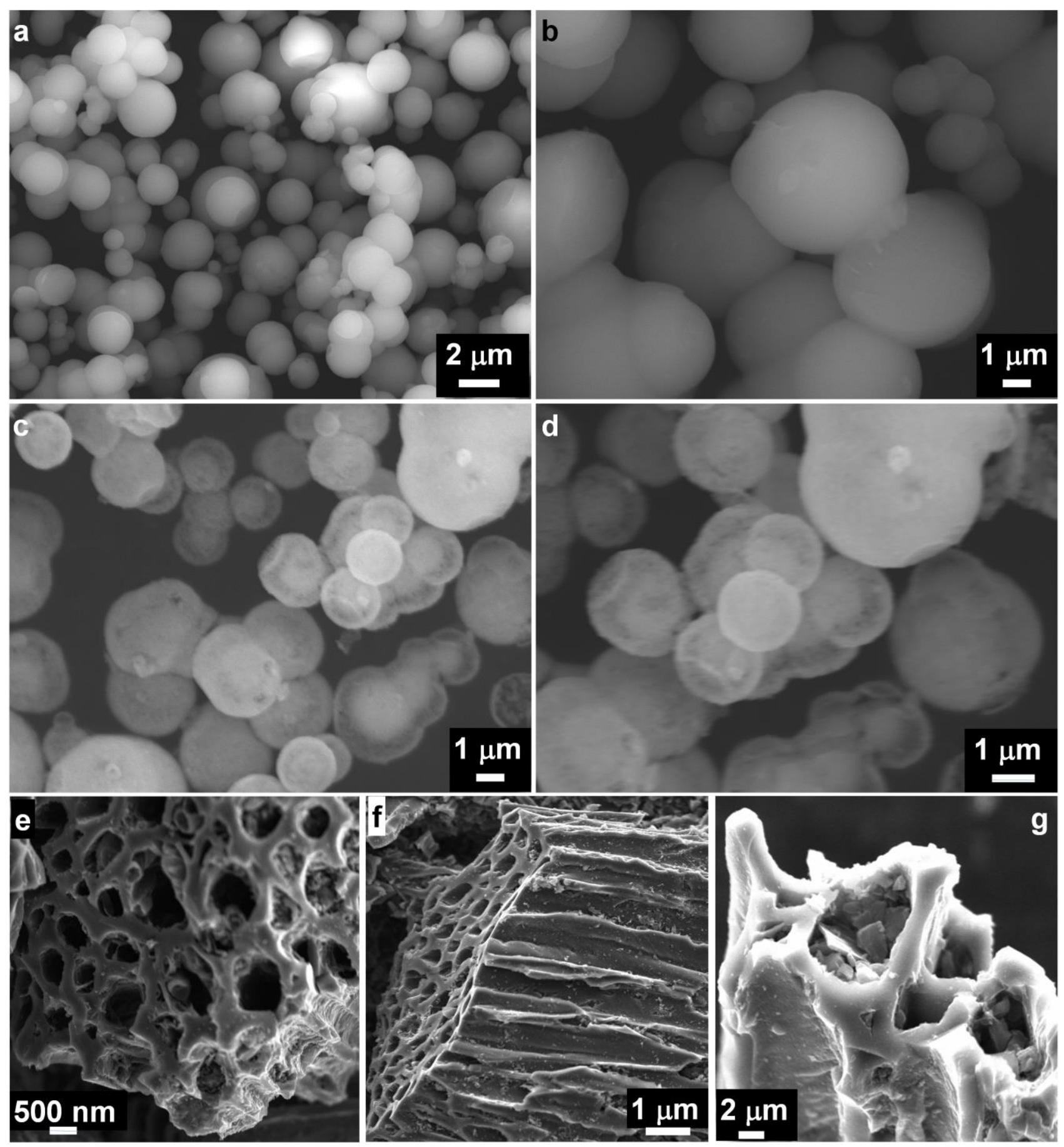

Figure 1. FE-SEM images of NiCo-MOF (a,b) before and (c,d) after annealing at $800{ }^{\circ} \mathrm{C}$ for $4 \mathrm{~h}$ and (e-g) PC. 


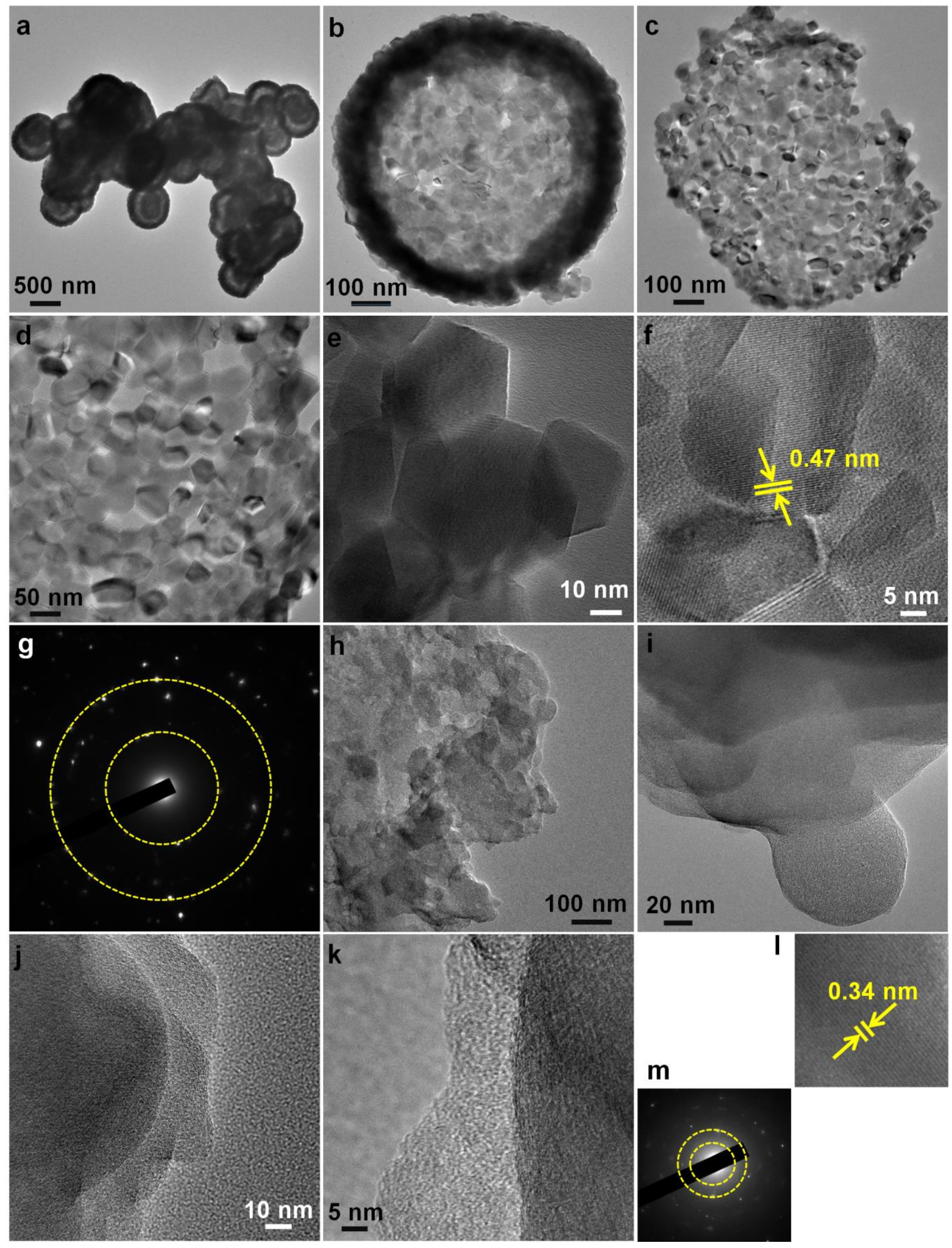

Figure 2. TEM images (a-d), lattice scale images (e,f), and SAED pattern (g) of annealed NiCo-MOF. TEM images (h-k), lattice scale image (l) and SAED pattern (m) of PC. 

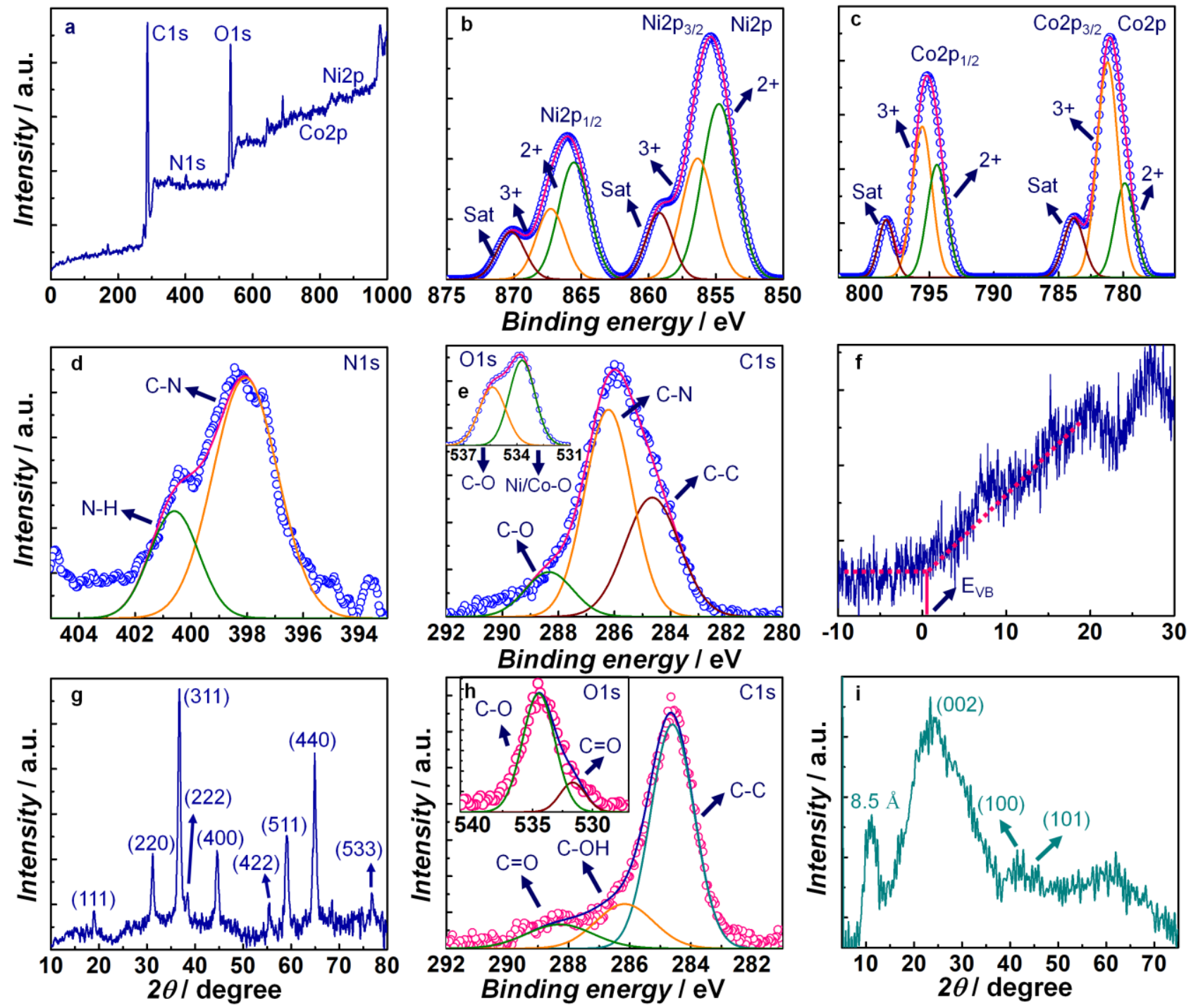

Figure 3. (a) XPS survey spectrum and deconvoluted core level spectra of (b) Ni2p, (c) Co2p, (d) N1s and (e) C1s (inset is O1s) and (f) VB spectrum of NiCo-MOF. (g) XRD pattern of NiCo-MOF. (h) Deconvoluted core level spectra of C1s and O1s (inset) and (i) XRD pattern of PC. 

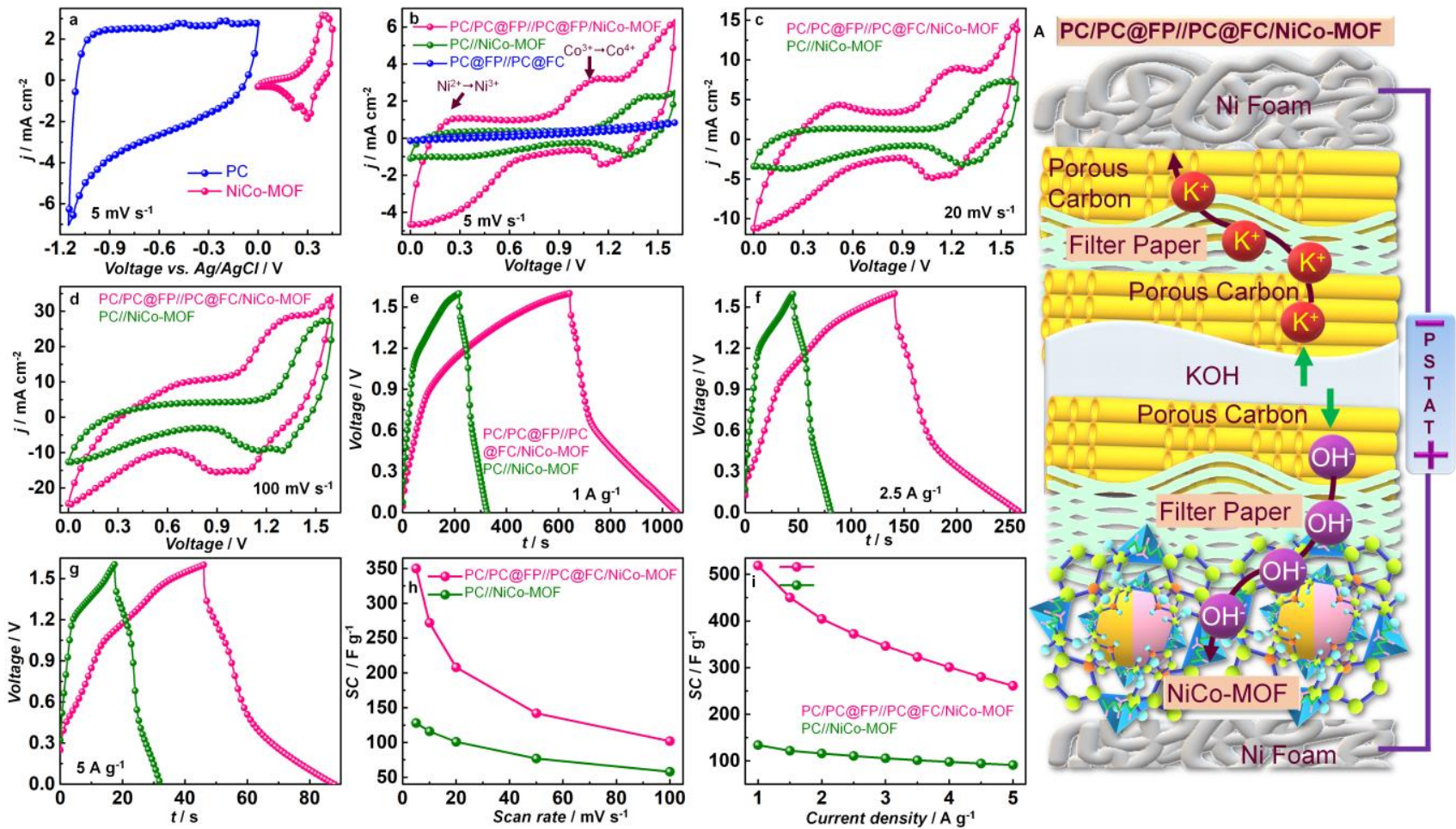

Figure 4. $\mathrm{CV}$ plots of $\mathrm{PC}$ and $\mathrm{NiCo}-\mathrm{MOF}$ in three electrode cells with $\mathrm{Ag} / \mathrm{AgCl} / \mathrm{KCl}$ and $\mathrm{Pt}$ as reference and counter electrodes, over potential ranges of -1.2 to $0 \mathrm{~V}$, and 0 to $0.4 \mathrm{~V}$. CV plots of different cells at (b) 5, (c) 20 and (d) $100 \mathrm{mV} \mathrm{s}^{-1}$ and GCD plots compared at (e) 1, (f) 2.5, (g) $5 \mathrm{~A} \mathrm{~g}^{-1}$ for the PC/PC@FP//PC@FP/NiCo-MOF and the PC//NiCo-MOF cells. Rate performance of the two cells compared using (h) $\mathrm{CV}$ and (i) GCD data. Schematic in panel A shows the movement of ions across the cross-section of the PC/PC@FP//PC@FP/NiCo-MOF cell. 

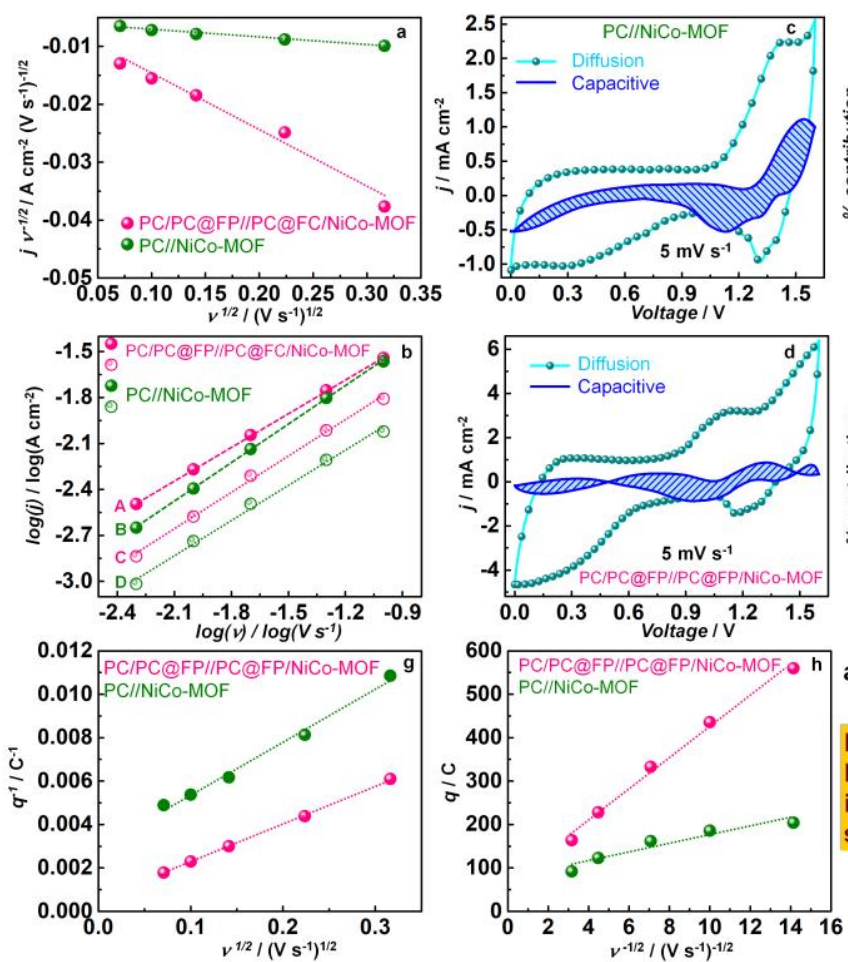
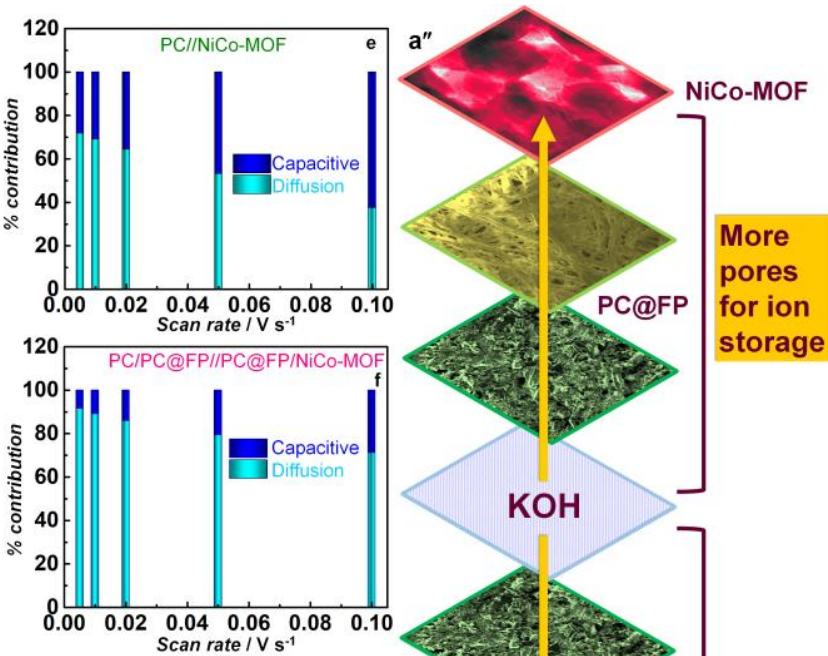

for ion

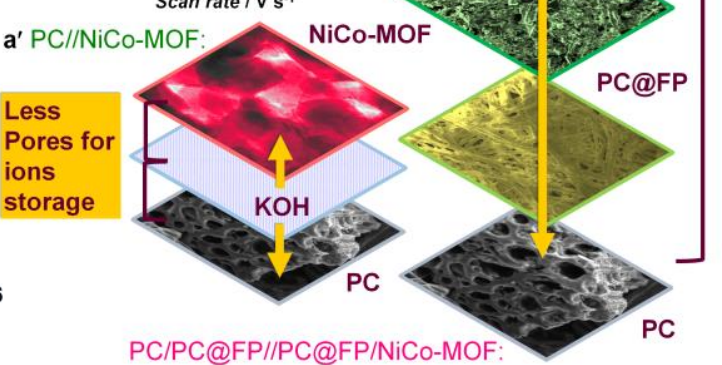

PC/PC@FP//PC@FP/NiCo-MOF

Figure 5. (a) $\left(\mathrm{j} \times \mathrm{v}^{-1 / 2}\right)$ versus $v^{1 / 2}$, and (b) $\log \mathrm{j}$ versus $\log v$ plots for the PC//NiCo-MOF and the PC/PC@FP//PC@ FP/NiCo-MOF cells. $\mathrm{CV}$ plots and \% contribution plots with diffusion and capacitive components for (c,e) the $\mathrm{PC} / / \mathrm{NiCo}-\mathrm{MOF}$ and $(\mathrm{d}, \mathrm{f})$ the PC/PC@FP//PC@FP/NiCo-MOF cells. (g) $1 / \mathrm{q}$ versus $v^{1 / 2}$ and $(\mathrm{h})$ q versus $v^{-1 / 2}$ for the PC//NiCo-MOF and the PC/PC@FP//PC@FP/NiCo-MOF cells. Schematics showing the $\left(\mathrm{a}^{\prime}\right)$ Lesser pore volume available for ions in the PC//NiCo-MOF cell and (a") relatively more pore volume available for ions in the PC/PC@FP//PC@FP/NiCo-MOF cell. 

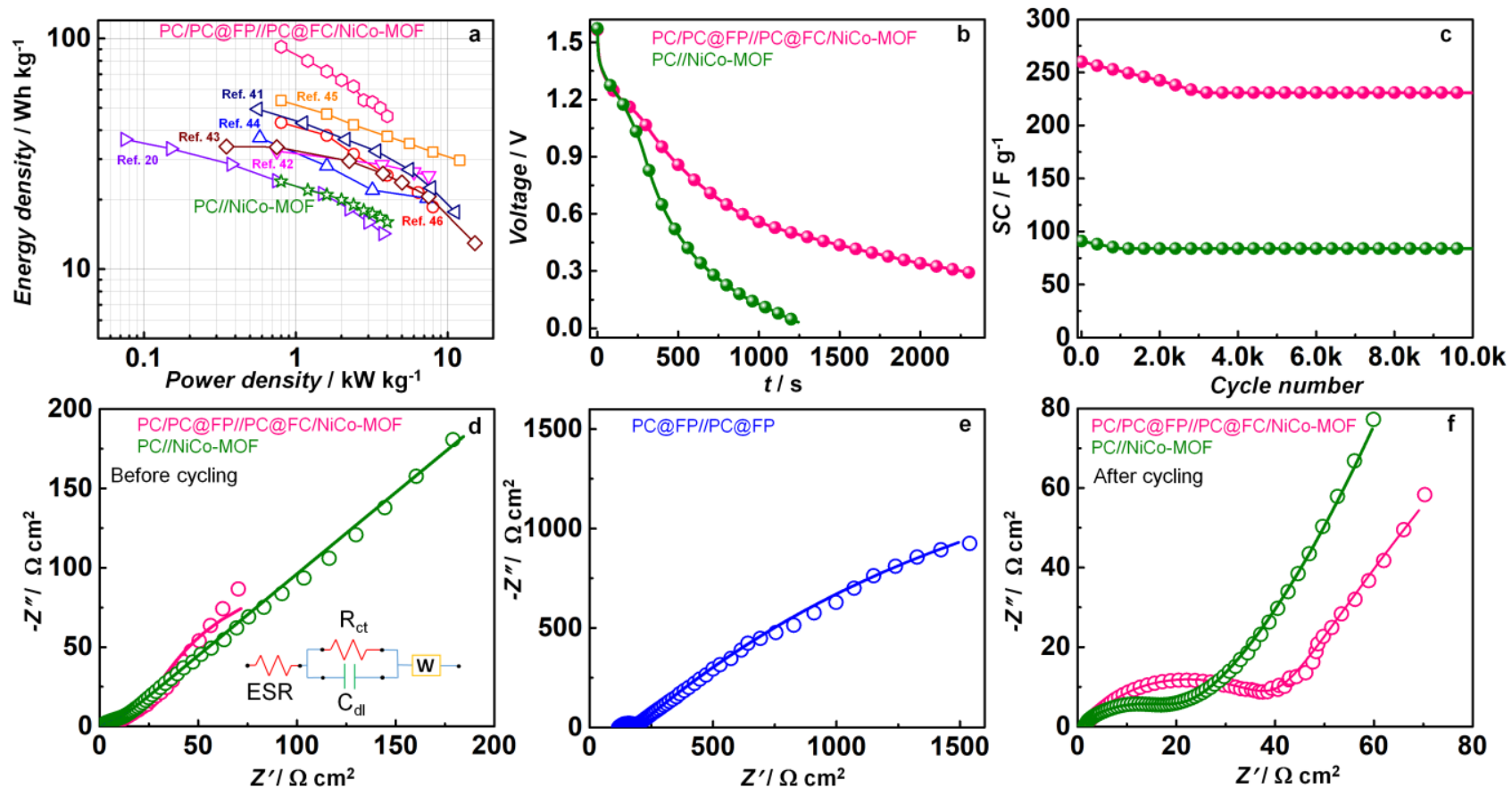

Figure 6. (a) Comparison of Ragone plots with literature data, (b) self-discharge plots, (c) variation of specific capacitance versus number of cycles for the PC//NiCo-MOF and the PC/PC@FP//PC@FP/NiCo-MOF cells. Nyquist plots (d,e) before cycling and (f) after cycling for different cells, recorded over a frequency range of $1 \mathrm{MHz}$ to $0.01 \mathrm{~Hz}$, at open-circuit potential, and by superimposing an ac potential of $20 \mathrm{mV}$. Inset of (a) is the equivalent circuit used for fitting all impedance data. 

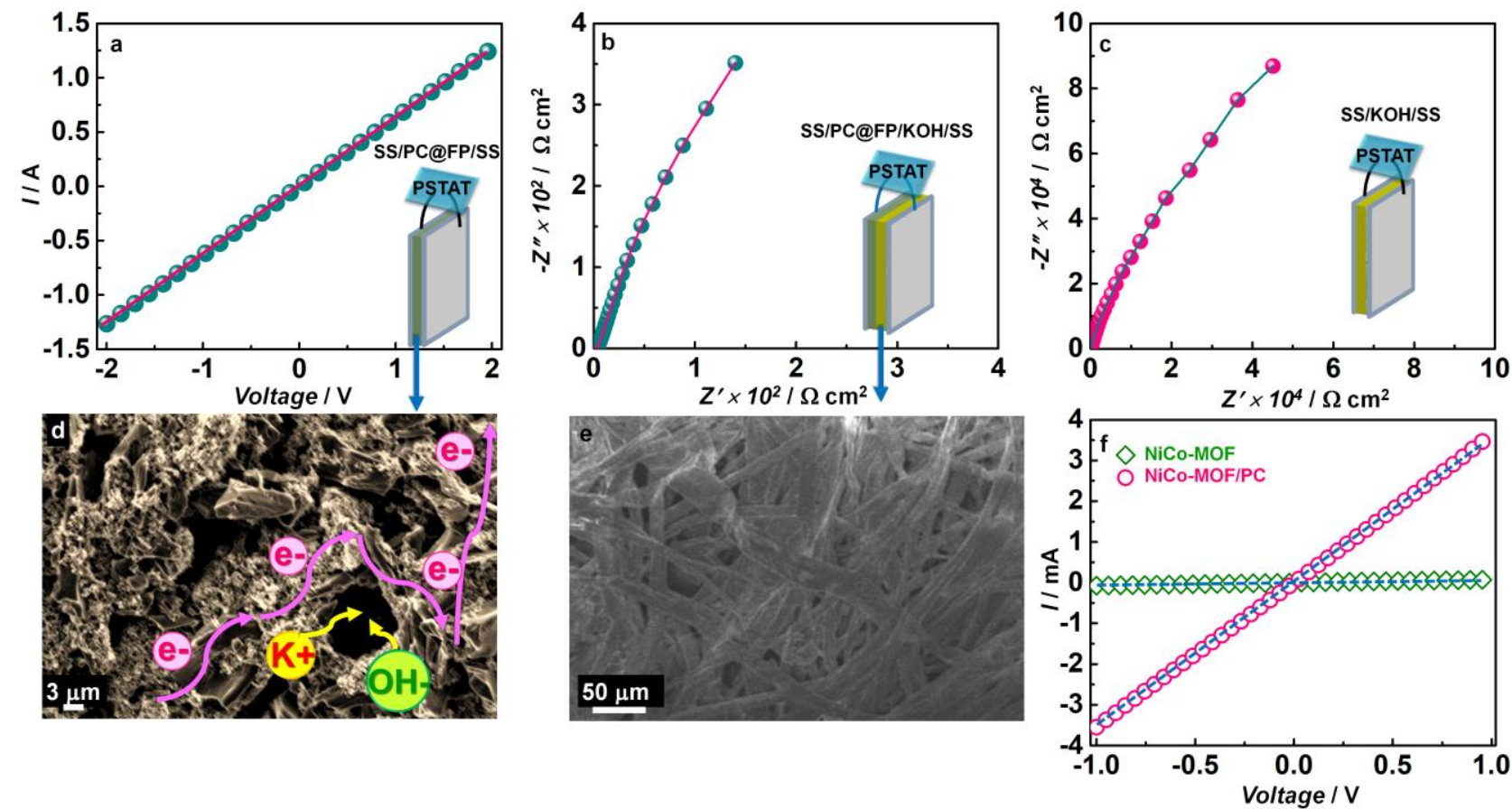

Figure 7. (a) I-V characteristics of SS/PC@FP/SS configuration. Nyquist plots of (b) SS/PC@FP/SS and (c) SS/PC@FP-KOH/SS configuration. SEM images of (d) PC@ $\mathrm{FP} / \mathrm{KOH}$ and (e) $\mathrm{KOH}$ over a frequency range of $1 \mathrm{MHz}$ and $0.01 \mathrm{~Hz}$. (f) I-V characteristics of $\mathrm{NiCo}-\mathrm{MOF}$ and NiCo-MOF/PC. 

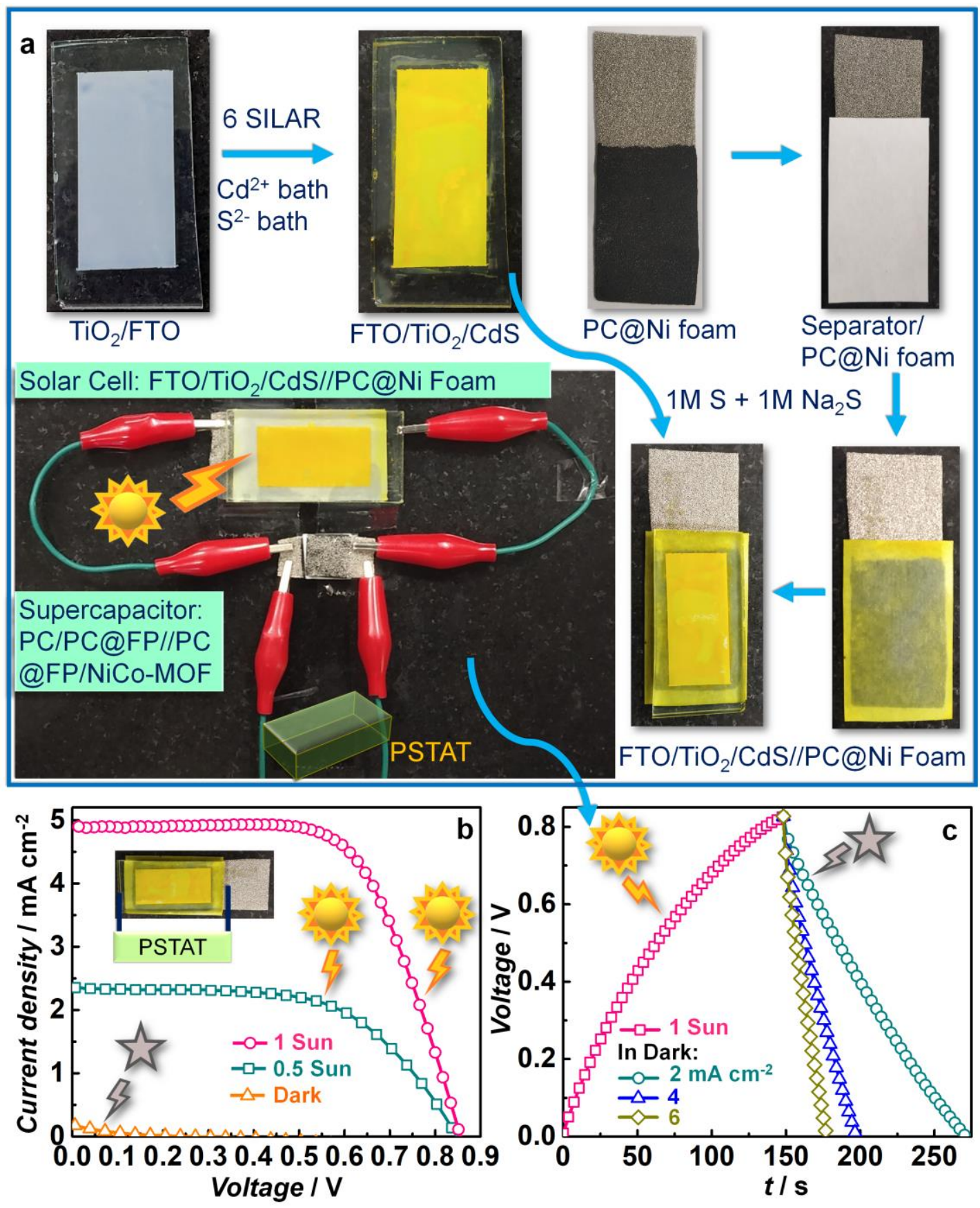

Figure 8. (a) Photographs illustrating the fabrication of a solution processed solar cell with a PC@Ni foam counter electrode, and a standalone assembly of the solar cell electrically connected with the PC/PC@FP//PC@FP/NiCo-MOF supercapacitor. (b) J-V characteristics of the solar cell: $\mathrm{TiO}_{2} / \mathrm{CdS} / \mathrm{S}^{2-}, \mathrm{S} / \mathrm{PC} @ \mathrm{Ni}$ foam, under dark and 0.5 and 1 sun irradiances. (c) Photo-charging of the supercapacitor under 1 sun irradiance, and galvanostatic discharging at different current densities in dark. 


\section{Graphical Abstract}

Stand-alone Low Cost Power Supply System:

NiCo-MOF/Porous Carbon@Filter Paper Supercapacitor-TiO $2 / C d S-C a r b o n$

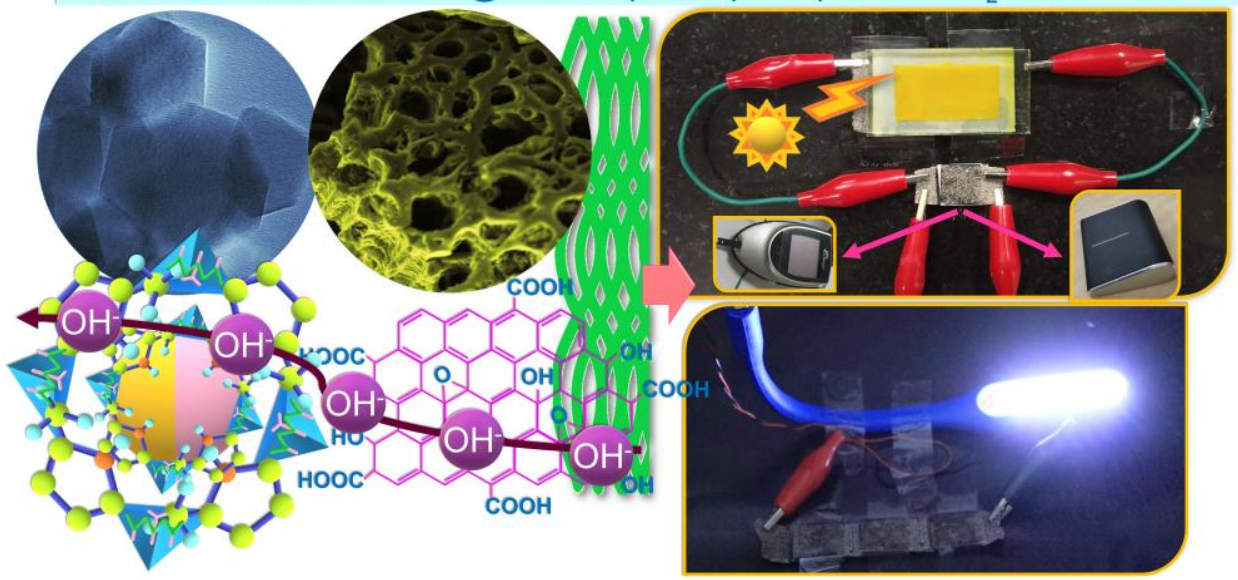

